\title{
SHALLOW-WATER MODELS FOR VOLCANIC GRANULAR FLOWS: A REVIEW OF STRENGTHS AND WEAKNESSES OF TITAN2D AND FLO2D NUMERICAL CODES
}

\author{
Francesco Neglia ${ }^{1,2}$, Roberto Sulpizio ${ }^{1,3,4}$, Fabio Dioguardi², Lucia Capra ${ }^{5}$, Damiano Sarocchi ${ }^{6}$
}

[1] University of Bari, Dipartimento di Scienze della Terra e Geoambientali, Bari, Italy

[2] British Geological Survey, The Lyell Centre, Edinburgh, United Kingdom

[3] INGV-Bologna section, Via D. Creti 12, Bologna, Italy

[4] IGAG-CNR, Via Salaria, 00015 Monterotondo, Rome, Italy

[5] Centro de Geociencias, UNAM, Querétaro, Mexico

[6] Departamento de Geologia, Facultad de Ingeneria, UASLP, San Luis Potosì, Mexico

\begin{abstract}
The behaviour of dry and wet volcanic granular flows is one of the main research topics in present day geophysics and volcanology. It involves various disciplines (e.g. sedimentology, geophysics, fluid dynamics) and investigation techniques (e.g. field studies, laboratory experiments, computational fluid dynamics). The vast interest is justified by the complex nature of these flows and their very dangerous nature that threaten millions of people around the world. In the last decade, computational fluid dynamics has become one of the main instruments used to reproduce past events of volcanic granular flows or to predict their behavior and potential hazard. In this study, we tested two of the most used codes for simulating volcanic granular flows, TITAN2D and FLO2D, against well studied natural cases (the 1998 wet granular flows in the Sarno area and the 2005 block and ash flows at Colima volcano) and large-scale experiments on granular flows. Comparison between simulated parameters and real ones were carried out in order to evaluate strengths and weaknesses of the two numerical codes. TITAN2D results showed how the basal friction angle is fundamental to control numerical simulations and its dependence on the topographic complexities and slope-angle ratio. Simulation of large scale experiments offered a good relationship between slope angle ratio at break in slope and basal friction angle, which is useful for application to small drainage basins with not complex channel morphology. FLO2D suffers the lack of rheometric parameters a and $B$ for volcaniclastic material, but is less sensitive of DEM resolution with respect to TITAN2D.
\end{abstract}

\section{Introduction}

The behaviour of dense volcanic flows (dry and wet granular flows) is one of the main research topics in present day geophysics and volcanology. It involves various disciplines (e.g. sedimentology, geophysics, fluid dynamics) and investigation techniques (e.g. field studies, laboratory experiments, computational fluid dynamics). The vast interest and effort dedicated to this research topic is 
justified by the complex nature of these flows and their very dangerous nature that threaten millions of people around the world.

Volcanic granular flows are gravity-driven current that can be classified as dry or wet. In the former, the motion is dominated by particle-particle collisions and particles-fluid interactions are negligible; in the latter, interstitial fluid effects and, in some cases cohesion cannot be neglected (Campbell 2006; Capra et al. 2011; Iverson and Vallance 2001; Sulpizio et al. 2010, 2016; Sulpizio and Dellino 2008). The distinguishing feature of volcanic granular flows is the intrinsic complexity of the solid phase, which is represented by volcanic sediments that usually show a wide range of sizes (from microns to meters), densities (from hundreds to few thousand of $\mathrm{kg} \mathrm{m}^{-3}$ ) and shapes (from almost spherical to highly irregular).

Wet granular flows in volcanic environment are also known as lahars. This term encompasses a wide range of wet granular flows, from debris flows (solid concentration $\varepsilon_{s}>0.5$ ) to hyperconcentrated flows $\left(\varepsilon_{s}=0.5-0.1\right)$ to muddy streamflows $\left(\varepsilon_{s}<0.1\right)$ (Vallance and Iverson 2015).

Both dry and wet granular flows are characterized by a high flow density, which causes large values of dynamic pressures that can potentially lead to the collapse of buildings and infrastructures. Additionally, these flows can inundate large areas, hence disrupting human activities like ground transportation, power lines, industry, agriculture, etc. (e.g. Zanchetta et al. 2004).

In the last few decades, computational fluid dynamics has become one of the main instruments used to predict the behaviour of dense volcanic flows (O'Brien et al. 1993; Patra et al. 2005; Kelfoun and Druitt 2005), possibly to quantify the hazard and eventually contribute to risk reduction in the future.

In this work, we present results of an analysis of the strengths and weaknesses of two of the most popular simulation tools for dense volcanic flows: TITAN2D (Patra et al. 2005; including two-phases TITAN2D, Pitman and Le, 2005) and FLO2D (O'Brien et al. 1993). Both codes solve for the depthaveraged shallow-water conservation equations describing the dynamics of the multiphase mixture composing these flows. We tested TITAN2D against large-scale experiments on granular flows (Sulpizio et al., 2016) and the 2005 block and ash flows at Volcan de Colima (Sulpizio et al., 2010). FLO2D and two-phases TITAN2D were tested against the 1998 wet granular flows in the Sarno area (Zanchetta et al., 2004). These applications allow us to investigate on the influence of the digital elevation model (DEM) resolution, topographic features and model-specific parameters on the simulation performance. In the following, we first briefly review the modelling approaches of 
TITAN2D and FLO2D. Second, we present individual model results of the selected test cases and, for the Sarno case-study, a comparison of the performance of the two models. Finally, we discuss the importance of input data selection on the results, including internal physical parameters and DEM resolution.

\section{The depth-averaged approach for the simulation of granular flows}

In the depth-averaged description, the fluid is approximated as an incompressible continuum material of constant density $\rho$ moving across a complex topography, in which the assumption is made that the horizontal length scales $L$ are substantially larger than the vertical length scale $H$ (shallow flows). If the aspect ratio $\varepsilon=H / L \rightarrow 0$, the vertical acceleration terms are small and the vertical force balance is usually expressed as a hydrostatic pressure balance (Saint-Venant 1871; Friedrichs 1948; Liggett 1994). The motion of the homogeneous incompressible continuum material can be described by means the mass and momentum conservation equations (Savage and Hutter 1989). The 3D mass conservation equation for an incompressible fluid is:

$$
\frac{\partial u}{\partial x}+\frac{\partial v}{\partial y}+\frac{\partial w}{\partial z}=0
$$

where $u, v$ and $w$ are the velocity components in the $x, y$ and $z$ directions, respectively. The momentum conservation equations equal the time rate of change of momentum to the sum of the applied forces, namely the stress divergence plus the gravity force. In horizontal-vertical Cartesian coordinates, the momentum equations are given by:

$$
\begin{aligned}
& \frac{\partial u}{\partial t}+u \frac{\partial u}{\partial x}+v \frac{\partial u}{\partial y}+w \frac{\partial u}{\partial z}=-\frac{1}{\rho}\left(\frac{\partial \tau_{x z}}{\partial x}+\frac{\partial \tau_{x y}}{\partial y}+\frac{\partial \tau_{x z}}{\partial z}-\rho g_{x}\right) \\
& \frac{\partial v}{\partial t}+u \frac{\partial v}{\partial x}+v \frac{\partial v}{\partial y}+w \frac{\partial v}{\partial z}=-\frac{1}{\rho}\left(\frac{\partial \tau_{y x}}{\partial x}+\frac{\partial \tau_{y y}}{\partial y}+\frac{\partial \tau_{y z}}{\partial z}-\rho g_{y}\right)
\end{aligned}
$$




$$
\frac{\partial w}{\partial t}+u \frac{\partial w}{\partial x}+v \frac{\partial w}{\partial y}+w \frac{\partial w}{\partial z}=-\frac{1}{\rho}\left(\frac{\partial \tau_{z x}}{\partial x}+\frac{\partial \tau_{z y}}{\partial y}+\frac{\partial \tau_{z z}}{\partial z}-\rho g_{z}\right)
$$

In which $g_{x}, g_{y}$ and $g_{z}$ are the gravitational acceleration components in the $x, y$ and $z$ direction, respectively, and $\boldsymbol{\tau}$ is the stress tensor.

Using the Leibniz rule together with free surface kinematic boundary condition, and integrating the Eq. 2 we obtain the depth-averaged $x$ momentum equation:

$$
\begin{aligned}
& \rho\left(\frac{\partial(h U)}{\partial t}+\frac{\partial\left(h U^{2}\right)}{\partial x}+\frac{\partial(h U V)}{\partial y}\right)-\rho\left(\left[u \frac{\partial z}{\partial t}+u^{2} \frac{\partial z}{\partial x}+u v \frac{\partial z}{\partial y}+u w\right]_{b}^{S}\right)=-\frac{\partial\left(h T_{x x)}\right.}{\partial x}-\frac{\partial\left(h T_{x y)}\right.}{\partial y}+ \\
& {\left[\tau_{x z}\right]_{b}^{S}+\rho g_{x} h}
\end{aligned}
$$

in which $T$ represents the depth-averaged value of stresses. The factor $h$ makes the individual terms of Eq. 5 conservative, giving significant advantages in numerical solution technique (Denlinger and Iverson 2001). The $y$ momentum equation can be obtained by interchanging $x-y, U-V$ and $u-$ $v$ in Eq. 5.

The depth-averaged approach above described is applicable to the mixture theory equations and to the equations solving solid-fluid mixtures as single-phase continua. TITAN2D and FLO2D, like other shallow-water models, follow the general scheme here reported but with different assumptions and constitutive equations. The flows described by the above equations will never stop and the mixture continues to move indefinitely, even if at very low velocities (Patra et al. 2005; O'Brien et al. 1993). This implies we have to introduce a flow stoppage criterion in order to obtain a finite runout (Yu et al. 2009).

\subsection{TITAN2D numerical model}

TITAN2D is designed to simulate dry geophysical mass flows over a real topography using the depthaveraged granular continuum approach (Savage and Hutter 1989, 1991; Patra et al. 2005). The conservation equations for mass and momentum are solved following the equations provided by Iverson and Denlinger (2001) in the dry limit, and taking into account a Coulomb-type friction term 
for the interactions between the granular medium and the basal surface (Pitman et al. 2003). For the derivation of the diagonal shear stress tensor components, TITAN2D uses the Mohr Coulomb theory, namely the depth-averaged stress $T_{x x}$ and $T_{y y}$ can be related to the normal stress $T_{z z}$ by:

$$
T_{x x}=T_{y y}=k_{a p} T_{z z}
$$

In which $k_{a p}$ is the lateral stress coefficient, whose formulation comes from the Mohr diagram:

$$
k_{a p}=2 \frac{1 \pm\left[1-\cos ^{2} \varphi_{\text {int }}\left(1+\tan ^{2} \varphi_{\text {bed }}\right)\right]^{\frac{1}{2}}}{\cos ^{2} \varphi_{\text {int }}}-1
$$

where the signs - and + correspond to an active (elongation) and a passive (compression) state, respectively, $\varphi_{\text {int }}$ is the internal friction angle and $\varphi_{\text {bed }}$ is the basal friction angle.

The shear stress at the basal surface $\tau_{z x}$ can be derived from the basal sliding law, for curving beds:

$$
\tau_{z x}=-\frac{U}{\sqrt{U^{2}+V^{2}}}\left[\rho g_{z} h\left(1+\frac{U}{r_{x} g_{z}}\right)\right] \times \tan \varphi_{b e d}
$$

where $r_{x}$ is the radius of local bed curvature, and the sign - indicates that the basal Coulomb stresses oppose basal sliding. The term $U / r_{x} g_{z}$ illustrates increase or decrease of normal stresses at the base of the mixture due to a variation of bed slope (bed concavity or convexity) (Iverson and Denlinger 2001). Using the kinetic boundary conditions and the relations for the diagonal shear stresses (Eq. 6 ) in the depth-averaged $x$ momentum equations (Eq. 5), we obtain the $x$ momentum conservation equation solved by TITAN2D:

$$
\begin{aligned}
& \frac{\partial(h U)}{\partial t}+\frac{\partial}{\partial x}\left(h U^{2}+\frac{1}{2} k_{a p} g_{z} h^{2}\right)+\frac{\partial(h U V)}{\partial y}=g_{x} h-h k_{a p} \operatorname{sgn}\left(\frac{\partial U}{\partial y}\right) \frac{\partial\left(g_{z} h\right)}{\partial y} \sin \varphi_{\text {int }}- \\
& \frac{U}{\sqrt{U^{2}+V^{2}}}\left[g_{z} h\left(1+\frac{U}{r_{x} g_{z}}\right)\right] \times \tan \varphi_{\text {bed }}
\end{aligned}
$$


The $y$ momentum equation is obtained by interchanging $x-y$ and $U-V$ in Eq. 9. It is worth noting how the shear stress at the basal surface directly depends from the value of $\varphi_{b e d}$, which is the only frictional term involved in Eq. 8.

The above description refers to a single-phase model and considers only dependence on solid phase Coulomb stresses, by neglecting any complex rheology of the mixtures.

A two-phases model has been implemented in TITAN2D, in which the flow is assumed to consist of a solid and fluid phase (Pitman and Le 2005). The two-phases model considers the fluid and the solid phase as an interpenetrating continuum, solving for continuity and momentum equations of the two phases. Pitman and Le (2005) vertically integrate the two-fluid equations of Anderson and Jackson (1967), obtaining the corresponding depth-averaged conservation equations (only the $x$ direction is reported):

$$
\begin{aligned}
& \frac{\partial h}{\partial t}+\frac{\partial\left(h\left(\overline{\varepsilon_{s}} U_{s}+\left(1-\overline{\varepsilon_{s}}\right) U_{f}\right)\right)}{\partial x}+\frac{\partial\left(h\left(\overline{\varepsilon_{s}} V_{s}+\left(1-\overline{\varepsilon_{s}}\right) V_{f}\right)\right)}{\partial y}=0 \\
& \frac{\partial\left(h \overline{\varepsilon_{s}} U_{s}\right)}{\partial t}+\frac{\partial\left(h \overline{\varepsilon_{s}} U_{s}^{2}\right)}{\partial x}+\frac{\partial\left(h \overline{\varepsilon_{s}} U_{s} V_{s}\right)}{\partial y}=-\frac{\epsilon}{2}\left(1-\frac{\rho_{f}}{\rho_{s}}\right) \frac{\partial\left(\alpha_{x x} h^{2} \overline{\varepsilon_{s}}\left(-g_{z}\right)\right)}{\partial x}-\frac{\epsilon}{2}\left(1-\frac{\rho_{f}}{\rho_{s}}\right) \frac{\partial\left(\alpha_{x y} h^{2} \overline{\varepsilon_{s}}\left(-g_{z}\right)\right)}{\partial y}- \\
& \frac{\epsilon}{2} \frac{\rho_{f}}{\rho_{s}} \overline{\varepsilon_{s}} \frac{\partial\left(h^{2}\left(-g_{z}\right)\right)}{\partial x}+\left(1-\frac{\rho_{f}}{\rho_{s}}\right)\left(-\epsilon \alpha_{x x} \frac{\partial b}{\partial x}--\epsilon \alpha_{x y} \frac{\partial b}{\partial y}+\alpha_{x z}\right) h^{2} \overline{\varepsilon_{s}}\left(-g_{z}\right)-\epsilon \frac{\rho_{f}}{\rho_{s}} h \overline{\varepsilon_{s}}\left(-g_{z}\right) \frac{\partial b}{\partial x}+ \\
& \left(1-\frac{\rho_{f}}{\rho_{s}}\right) \frac{h\left(1-\overline{\varepsilon_{s}}\right) \overline{\varepsilon_{s}}}{v_{t}\left(1-\overline{\varepsilon_{s}}\right)^{m}}\left(U_{f}-U_{s}\right)+h \overline{\varepsilon_{s}} g_{x} \\
& \frac{\partial\left(h U_{f}\right)}{\partial t}+\frac{\partial\left(h U_{f}^{2}\right)}{\partial x}+\frac{\partial\left(h U_{f} V_{f}\right)}{\partial y}=-\frac{\epsilon}{2} \frac{\partial h^{2}\left(-g_{z}\right)}{\partial x}-\left(\frac{1-\frac{\rho_{f}}{\rho_{s}}}{\frac{\rho_{f}}{\rho_{s}}}\right) \frac{h \overline{\varepsilon_{s}}}{v_{t}\left(1-\overline{\varepsilon_{s}}\right)^{m}}\left(U_{f}-U_{s}\right)+h g_{x}
\end{aligned}
$$

in which $\overline{\varepsilon_{S}}$ is the depth-averaged solid volume fraction, $\epsilon$ comes from scaling of the equations and represents the ratio of vertical length scale and horizontal length scale, $\alpha_{* *}$ is the lateral stress coefficient in the $x$ and $y$ directions, $v_{t}$ is the terminal velocity of an isolated representative solid particle falling in the fluid and $m$ is a coefficient that depends from Reynolds number. Eq. 10 represents the depth-averaged continuity equation for the mixture, Eqs. 11 and 12 are the depthaveraged momentum equations for the solid and fluid phase, respectively. We refer the reader to Pitman and Le (2005) for more details. 
The two-phases model is able to calculate fluid and solid velocity by momentum equations taking advantage over the single-phase model of Patra (2005) or otherwise, over the continuum mixture models (Iverson and Denlinger 2001; Iverson 1997). Indeed, in the equations of continuum mixture models, motion of fluid relative to the solid is assumed as small as the fluid velocity and acceleration differ negligibly from those of the solids (Iverson and Denlinger 2001). Furthermore, buoyancy effect coupled with pore fluid pressure, reduces the normal force acting on the surface, reducing kinetic energy dissipation by basal friction (Pitman and Le 2005). This results in fluidization of the wet granular flows, which increases its runout.

In order to run a typical TITAN2D simulation, the user needs: 1) DEM of the area of interest; 2) the volume of the mobilized granular material, which is released (motion initiation) as a pile of material with user-specified dimensions of height, width and thickness to be placed in the computational domain; 3 ) the scale length, a scale factor that refers to the expected runout length of the flows and that helps to reduce the occurrence of round-off errors and the tendency of some layers to develop unrealistic high velocities; 4) the initial grid size and the smallest computational cell allowed on the map during the course of the simulation, since TITAN2D allows the use an adaptive mesh (Patra et al. 2005); 5) the internal friction angle $\left.\varphi_{\text {int }} ; 6\right)$ the basal friction angle $\varphi_{\text {bed }}$; and, 7) the solid phase concentration $\varepsilon_{S}$ if the two-phases model is used.

\subsection{FLO2D numerical model}

FLO2D is designed to route non-Newtonian flows, estimating the main flow properties and predicting plausible inundated areas. This code solves the full dynamic wave equation and considers the interactions with obstructions and constructions that characterise the urban areas ( $\mathrm{O}^{\prime}$ Brien et al. 1993).

Several complex processes affected the rheological behaviour of wet granular flows. In particular, the cohesion between fine particles increases the yield stress and the viscous stress, which must be exceeded by an exerted stress to initiate the fluid motion. Particle-particle collisions generate the dispersive stress. If the water-solid mixture is sufficiently dilute to generate a hyperconcentrated flow, also the turbulent stress needs to be taken into account. By adding the above-mentioned stresses, O'Brien et al. (1993) calculated the total shear stress: 


$$
\tau=\tau_{c}+\tau_{m c}+\tau_{v}+\tau_{t}+\tau_{d}
$$

where $\tau_{c}$ is the cohesive yield stress, $\tau_{m c}=P_{s} \tan \varphi_{\text {int }}$ is the Mohr-Coulomb shear stress that depends on the intergranular pressure $P_{S}$ and the internal friction angle $\varphi_{\text {int }}, \tau_{v}$ is the viscous stress, $\tau_{t}$ is the turbulent shear stress and $\tau_{d}$ is the dispersive shear stress. This formulation has the advantage to take into account fundamental processes taking place in debris and hyperconcentrated flows, such as the interaction of non-cohesive sediment developing dispersive stresses and the cohesiveness of flows with a high proportion of fine sediment, where viscous forces dominate flow behaviour. On the other hand, in the FLO2D formulation the inertial stresses are less important than viscous stresses.

In FLO2D, Eq. 13 is depth integrated and rewritten in the form of a dimensionless slope (O'Brien et al. 1993):

$$
S_{f}=S_{y}+S_{v}+S_{t d}
$$

$S_{f}$ is the total slope-friction and is equal to the sum of the various slope components, the yield slope $S_{y}$ (which accounts for both the cohesive and the Mohr-Coulomb yield), the viscous slope $S_{v}$ and the turbulent dispersive slope $S_{t d}$. The slope shear stress can be rewritten as:

$$
S_{f}=\frac{\tau_{y}}{\gamma_{m} h}+\frac{K \eta U}{8 \gamma_{m} h^{2}}+\frac{n_{t d}^{2} U^{2}}{h^{4 / 3}}
$$

where $K$ is an empirical resistance parameter which increases with roughness and irregular cross section geometry, $\eta$ is fluid viscosity, $n_{t d}$ is the Manning roughness coefficient, which represents the channel's resistance to flow and $\gamma_{m}$ is the specific weight of the sediment mixture.

The yield stress $\tau_{y}$ and the viscosity $\eta$ vary mainly with silt, clay and fine sand concentration. FLO2D calculates these terms via empirical relationship (O'Brien and Julien 1988):

$$
\begin{gathered}
\tau_{y}=\alpha_{2} e^{\beta_{2} \varepsilon_{s}} \\
\eta=\alpha_{1} e^{\beta_{1} \varepsilon_{s}}
\end{gathered}
$$


in which $\alpha_{i}$ and $\beta_{i}$ are empirical coefficient that depend on the material and can be obtained by laboratory experiments. A table listing the coefficients $\alpha_{i}$ and $\beta_{i}$ for different sediment types and concentrations is available in O'Brien and Julien (1988).

By depth-averaging and considering the dimensionless slope terms, the momentum equations solved in FLO2D are (O'Brien et al., 1993):

$$
\begin{aligned}
& \frac{\partial h}{\partial t}+\frac{\partial(U h)}{\partial x}+\frac{\partial(V h)}{\partial y}=i \\
& S_{f x}=S_{o x}-\frac{\partial h}{\partial x}-\frac{\partial(U)}{\partial t}-\frac{\partial\left(U^{2}\right)}{\partial x}-\frac{\partial(U V)}{\partial y} \\
& S_{f y}=S_{o y}-\frac{\partial h}{\partial y}-\frac{\partial(V)}{\partial t}-\frac{\partial\left(V^{2}\right)}{\partial y}-\frac{\partial(V U)}{\partial x}
\end{aligned}
$$

where $i$ is the excess rainfall intensity, which may be nonzero. The component of total slope-friction $S_{f x}$ and $S_{f y}$ are written as a function of bed slopes $S_{o x}$ and $S_{o y}$, pressure gradient and local and convective acceleration components.

To run a typical FLO2D simulation, the user needs: 1 ) the inflow hydrograph (rate of flow discharge versus time); 2 ) the Manning $n_{t d}$ values; 3) rheological parameters $\alpha$ and $\beta$; 4) the laminar flow resistance $K$; and, 5) the limiting Froude number $F r_{\min }$ that forces the subcritical regime in the flow, which is a prerequisite for numerical stability (Jia 1990), controlling the formation of numerical instabilities.

\section{Case studies}

We selected some very different case studies in order to test the main strengths and weaknesses of TITAN2D and FLO2D codes in simulating real dry and wet granular flows. The dry tests were carried out using TITAN2D for simulating laboratory experiments (Sulpizio et al. 2016) and natural blockand-ash flows (BAFs) at Volcan de Colima (Mexico; Sulpizio et al., 2010). The wet tests were carried out using two-phases TITAN2D and FLO2D for simulating the volcaniclastic flows occurred on May 
5-6, 1998 at Sarno,Italy (Zanchetta et al., 2004). The Sarno case also allows a direct comparison of the two numerical codes.

\subsection{Dry case \#1: large-scale experiments of granular flows}

Large-scale experiments were carried out at the University of San Luis Potosì (UASLP, Mexico), in order to investigate the dynamics of granular material passing over a break slope. The experimental setup (Fig. 1) is composed of a container that can be filled with granular material with a remotely controlled electromagnetic opening system, a 5-m long and 0.3-m wide flume with an adjustable slope and a less inclined (between $0^{\circ}$ and $20^{\circ}$ ) expansion box, where the flow decelerates and deposits. Flow front propagation velocity and basal load are detected by arrays of fourteen laser detectors and five load cells. In the experiments, the effect of the slope-angle ratio (SAR), which is given by the slope ratio of expansion box and upstream channel, on the final deposit was investigated. Different experimental configurations, with SAR between 0 and 0.5 were simulated. The weight of experimental material, composed of poorly vesicular dacitic clasts $\left(\rho_{s} \cong\right.$ $2300 \mathrm{~kg} \mathrm{~m}^{-3}$ ) with a Weibull grain size distribution, was set at $50 \mathrm{~kg}$ in all the considered experimental runs. Collected data were used to obtain relationships between SAR, velocity, runout and shape deposits (Sulpizio et al., 2016).
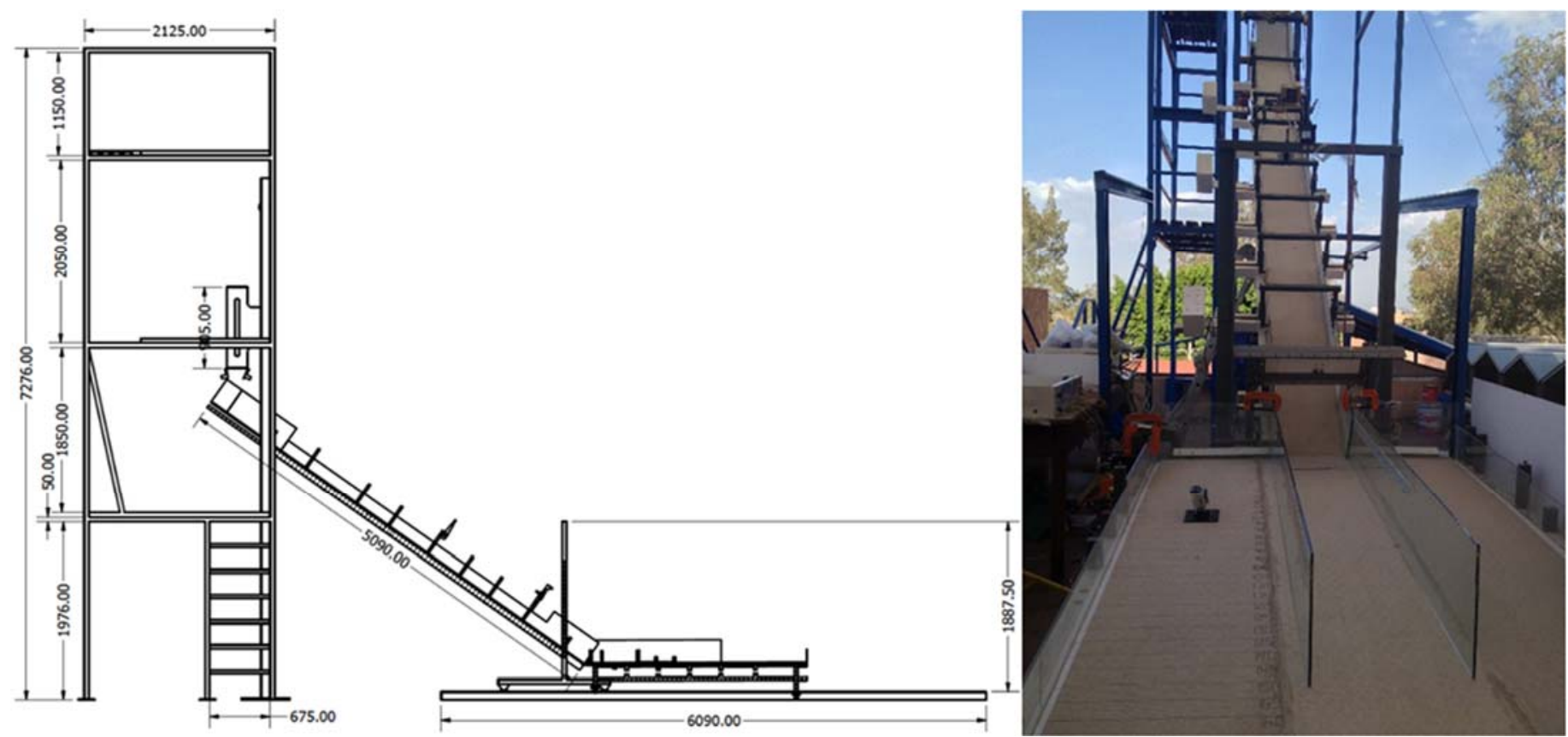

Figure 1. Scheme of the laboratory apparatus (from Sulpizio et al., 2016). 


\subsection{Dry case \#2: The June 9, 2005 block and ash flows at Colima}

The Volcan de Colima is a volcanic edifice with a summit elevation of 4,260 m a.s.l., located along the Trans Mexican Volcanic Belt, in Colima region (Mexico) (Fig. 2). It is one of the most active volcanoes in the world, and its eruptive activity is characterised by repetitive growing and collapses of Merapi and Soufriere dome type, Vulcanian and Plinian explosive eruptions, and extrusions of lava flows (Saucedo et al. 2005; Macías et al. 2006; Luhr et al. 2010; Capra et al. 2011). Usually collapse of summit domes generates pyroclastic density currents (PDCs), which inundate the upper slopes of the volcano and engulf the deep and incised valleys at the base of the main cone (Sulpizio et al. 2010; Sarocchi et al. 2011).

Most of the PDC deposits recognized at Volcan de Colima were generated by BAFs from the collapse of eruptive columns and domes. The case study refers to the activity started at the end of September 2004, with the formation of a summit dome. Between February and September 2005 several major Vulcanian explosions occurred, generating an undetermined number of BAFs. The BAF of the June 9, 2005 was emplaced along the La Arena ravine (Fig. 2) with a runout of $5400 \mathrm{~m}$ (Macías et al., 2006; Stevenson and Varley, 2008; Gavilanes-Ruiz et al., 2009).

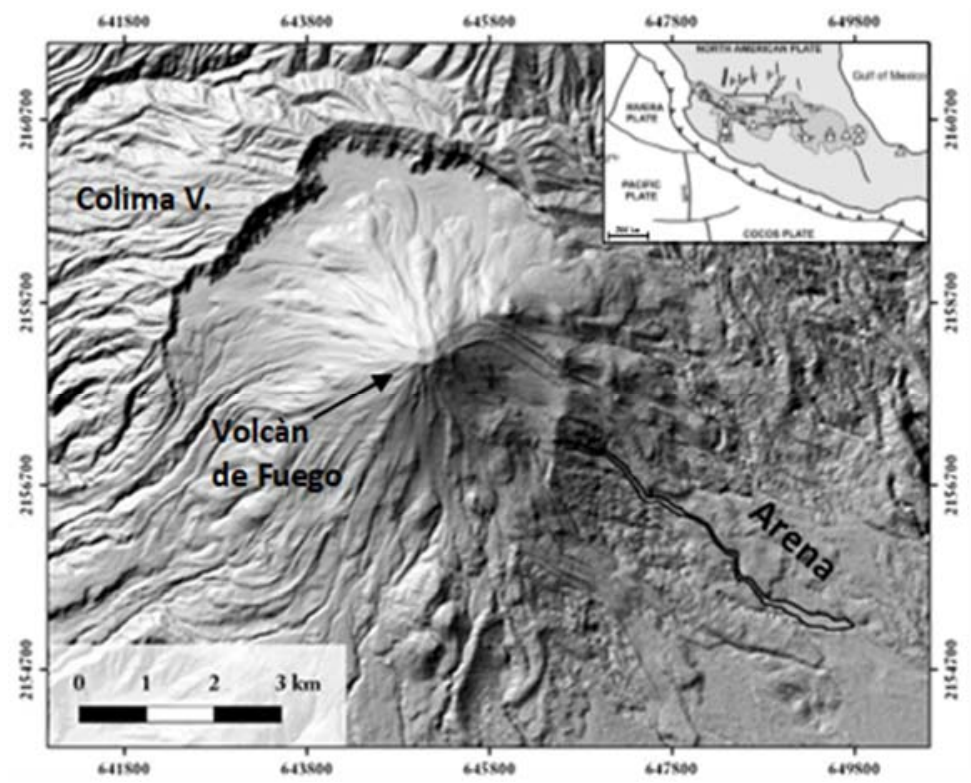

Figure 2. Colima image showing the distribution of block-and-ash flow deposits along the Arena ravine (from Sulpizio et al., 2010). In the insert at the top right the Trans-Mexican Volcanic Belt and the Colima Volcanic Complex (CVC).

3.3 Wet case: The May 5-6, 1998 volcaniclastic flows in the Sarno area (Italy) 
Sarno is located in southern Campania (Italy), downwind of Somma-Vesuvius and Campi Flegrei volcanoes. The rugged and steep relief of Sarno area is made up of Meso-Cenozoic limestones covered by loose to poorly consolidated volcaniclastic deposits, deriving mainly from the explosive activity of the Somma-Vesuvius volcano (Pareschi et al. 1998, 2002). The proneness of steep relief and rainfall regime to generate volcaniclastic flows was tragically shown on May 5-6, 1998, when the Sarno area was struck by tens of these flows initiated as soil slips triggered by prolonged rainfall (Fig. 3; e.g. Braca and Onorati, 1998; de Riso et al., 1999; Brancaccio et al., 2000; Cascini et al., 2000; Calcaterra et al., 2000; Chirico et al., 2000; Pareschi et al., 2000; Zanchetta et al., 2004).

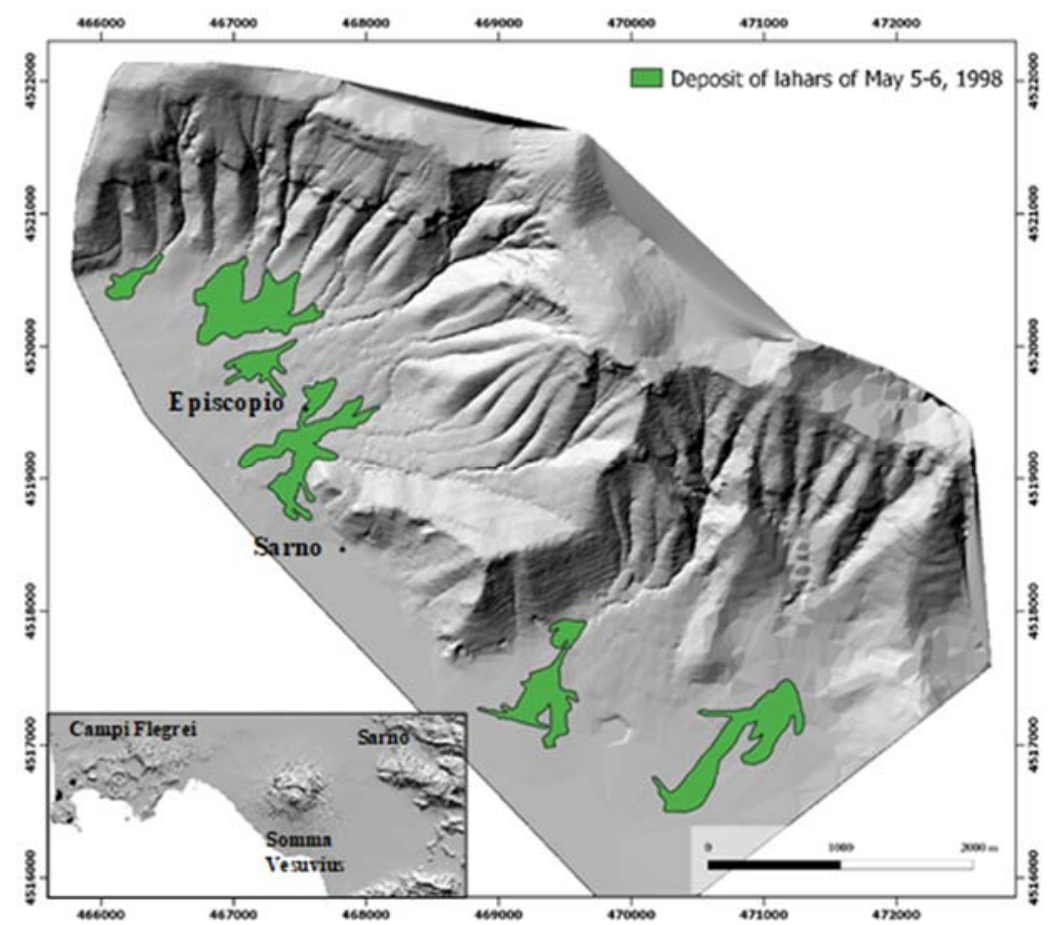

Figure 3. Shadow-relief of Sarno-Episcopio area. In green the areal distribution of the deposit of lahars detected by Zanchetta et al. (2004). The different deposit areas are labelled as Ep for the Episcopio area and Lav for the Lavorate area. In the inset the regional location of the Sarno-Episcopio area.

\section{Application of the numerical models to the case studies}

\subsection{Simulations of dry case \#1 (large-scale experiments)}

The large-scale experiments on granular flows were simulated with TITAN2D. In this case, we changed the basal friction angle $\left(\varphi_{b e d}\right)$ in order to fit the flow runouts at varying SAR. The pyroclastic material volume was set at $0.036 \mathrm{~m}^{3}$ and the internal friction angle at $30^{\circ}$, in agreement with other applications of TITAN2D to simulate dry granular (Capra et al., 2008; Charbonnier and Gertisser, 
2009; Sulpizio et al., 2010). Simulations were performed on a DEM with $0.01 \mathrm{~m} / \mathrm{pixel}$ horizontal resolution. In TITAN2D, it is not possible to simulate material falling into the channel. Therefore, the experimental granular flows were simulated as a pile on the flume with an initial velocity of 4.07 $\mathrm{m} / \mathrm{s}$, which correspond to the initial velocity recorded during the experiments (Sulpizio et al., 2016). The simulations were run for the different experimental set ups (different SAR) used by Sulpizio et al. (2016), in order to select the basal friction angles providing the best fit between real and simulated granular flows (Fig. 4). The simulated and observed morphometric data are reported in
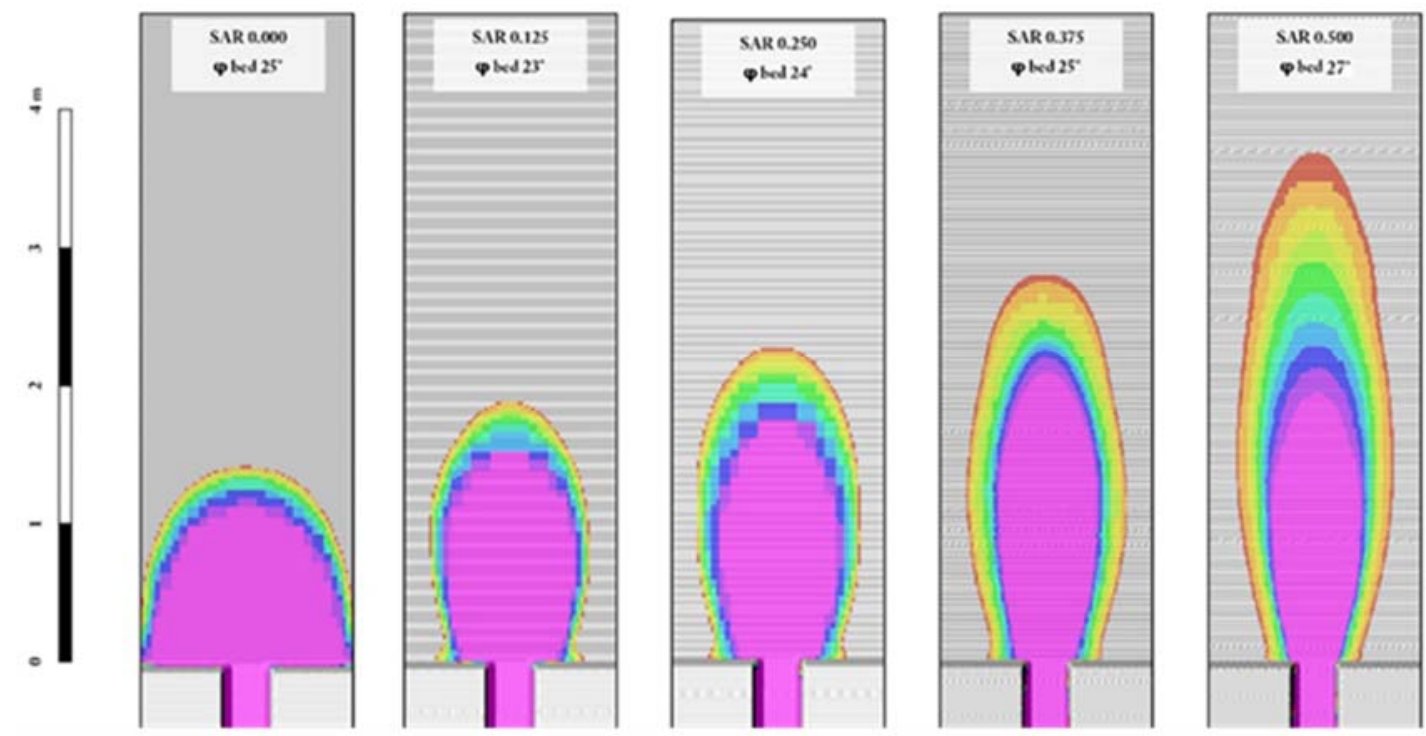

Thickness ( $\mathrm{m})$

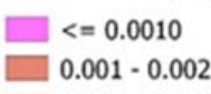

$0.002-0.003$

$0.003-0.004$

ए $0.004 \cdot 0.005$

$0.005-0.006$

$\square .006-0.007$

$0.007-0.008$

$0.008-0.009$

$0.009-0.01$

— $0.01-0.1$

\section{Table 1 and in Figure 5.}




\begin{tabular}{|lccc|cccc|}
\hline \multicolumn{3}{|c|}{ Real morphometric data } & \multicolumn{3}{c|}{ Simulated morphometric data } \\
\hline SAR & Area $\left(\mathrm{m}^{2}\right)$ & a-axis body $(\mathrm{m})$ & b-axis body $(\mathrm{m})$ & Area $\left(\mathrm{m}^{2}\right)$ & a-axis body $(\mathrm{m})$ & b-axis body $(\mathrm{m})$ & optimal $\varphi_{\text {bed }}\left({ }^{\circ}\right)$ \\
0.000 & 0.84 & 0.73 & 0.37 & 1.62 & 0.73 & 0.71 & 25 \\
0.125 & 1.14 & 0.93 & 0.39 & 1.71 & 0.94 & 0.58 & 23 \\
0.250 & 1.51 & 1.17 & 0.41 & 2.09 & 1.13 & 0.59 & 24 \\
0.375 & 1.98 & 1.43 & 0.44 & 2.52 & 1.41 & 0.57 & 25 \\
0.500 & 2.50 & 1.81 & 0.44 & 3.29 & 1.84 & 0.57 & 27 \\
\hline
\end{tabular}

Table 1. Experimental and simulated morphometric data.
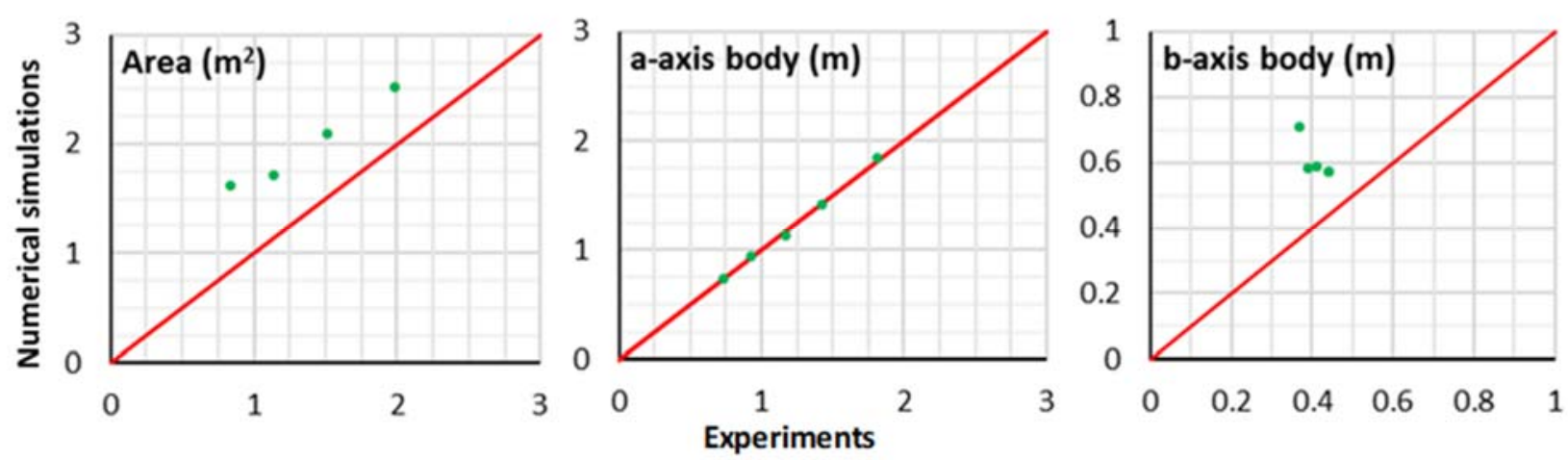

Figure 5. Comparison of real and simulated data. The solid red line represents perfect match between real and simulated values.

The visual inspection of the shape of the simulated and experimental deposits shows an unrealistic shape of the simulated experiment with SAR $=0$ (Fig. 4), while the comparison of real and simulated shapes is closely similar at increasing SAR (Fig. 4).

The area and $b$-axis are always overestimated in the numerical simulations, while the match is very good for a-axis (runout). This is not surprising, being the real a-axis used to find the optimal basal friction angle of the numerical simulations. 
The simulated shape for SAR $=0$ is completely not real because deposits tend to have unrealistic shape in proximity of the channel exit (Fig. 4), deposit area is $93.9 \%$ greater than observed one and the optimum value of $\varphi_{\text {bed }}$ deviates from SAR/ $\varphi_{\text {bed }}$ trend shown in Figure 6.

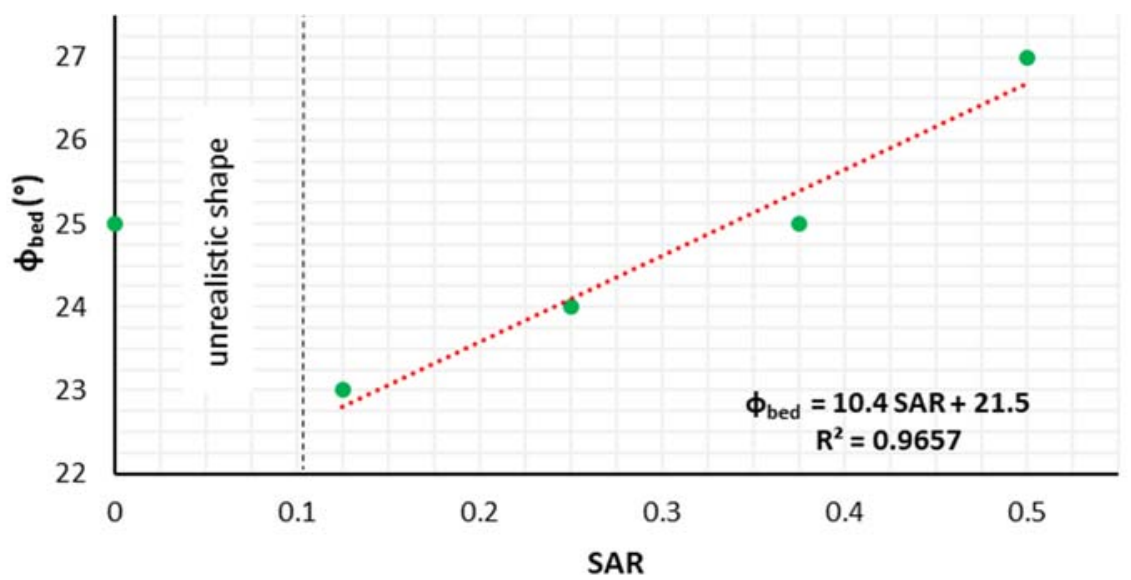

Figure 6. Basal friction angle $\left(\varphi_{\text {bed }}\right)$ plotted against the slope angle ratio (SAR). The dotted black lines separate the unrealistic and realistic shape of deposits of Figure 4. Dotted red line is the linear regression linking $\varphi_{\text {bed }}$ and SAR, respectively.

For these reasons, the data from $S A R=0$ simulation were not considered for tracing the regression line in Figure 6.

Data for SAR $>0$ show how the basal friction angle used for matching the experimental runouts is very sensitive to the slope-angle ratio (Fig. 6), with a good linear relationship between $\varphi_{\text {bed }}$ and SAR. Although based on relatively few points, the linear regression indicates a first order dependence between SAR and $\varphi_{\text {bed }}$, which represents a simple empirical method for the selection of $\varphi_{\text {bed }}$ on the basis of the slope-angle ratio. Clearly, SAR is just one among many factors that influence $\varphi_{\text {bed }}$ in nature (e.g. basal roughness, channel irregularity, obstacles, etc.), which will be discussed in the following.

\subsection{Simulations of dry case \#2 (block-and-ash flows at Colima)}

The block-and-ash flow of the June 9, 2005 of La Arena ravine was simulated using TITAN2D. Simulations were performed on a DEM with $10 \mathrm{~m} /$ pixel horizontal resolution. The volume of the collapsed pile was initialized as a sphere with a volume of $5 \times 10^{5} \mathrm{~m}^{3}$ (Sulpizio et al. 2010). The internal friction angle was set to $30^{\circ}$ for all simulations. 
With the aim of investigating the influence of the basal friction angle on the model's outputs, different simulations were carried out varying the value of $\varphi_{\text {bed }}$ in the range between $11^{\circ}$ and $25^{\circ}$. We quantitatively evaluated the performance of the simulations by comparing the simulated runout with the observed one by means of the percent length ratio:

$R_{l}=\frac{L_{\text {sim }}}{L_{\text {obs }}} \times 100$

where $L_{\text {sim }}$ is the simulated flow runout and $L_{\text {obs }}$ is the observed flow runout (Spataro et al., 2004). It is to note that we considered only the areas where the main basal flow units were emplaced, thus not taking into account the smaller flows that covered the summit part of the ravines due to the lack of direct observations (Sulpizio et al., 2010). For this reason, a comparison between observed and simulated inundated areas was not possible.

The 2005 BAF of La Arena was best reproduced with a basal friction angle of $13^{\circ}$ (Figs. 7 and 8 ), which resulted in a simulated runout $1.4 \%$ lower than the observed one. Longer (8-19 \%) or shorter (12-35\%) runouts were instead obtained for the other values of $\varphi_{\text {bed }}$ (Fig. 7). The observed BAF thickness reaches a maximum value of ca. $2.6 \mathrm{~m}$ along the main channel (Sulpizio et al., 2010), which is in good agreement with the simulated thickness of ca. $3 \mathrm{~m}$ (Fig. 8).

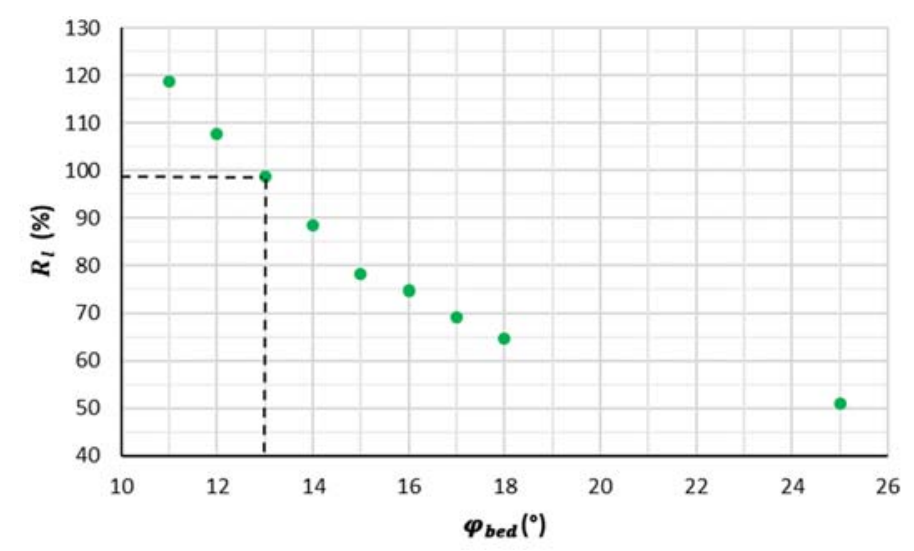

Figure 7. Basal friction angles plotted against percent length ratios. The dotted black lines mark the optimal value of $\varphi_{\text {bed }}$. 

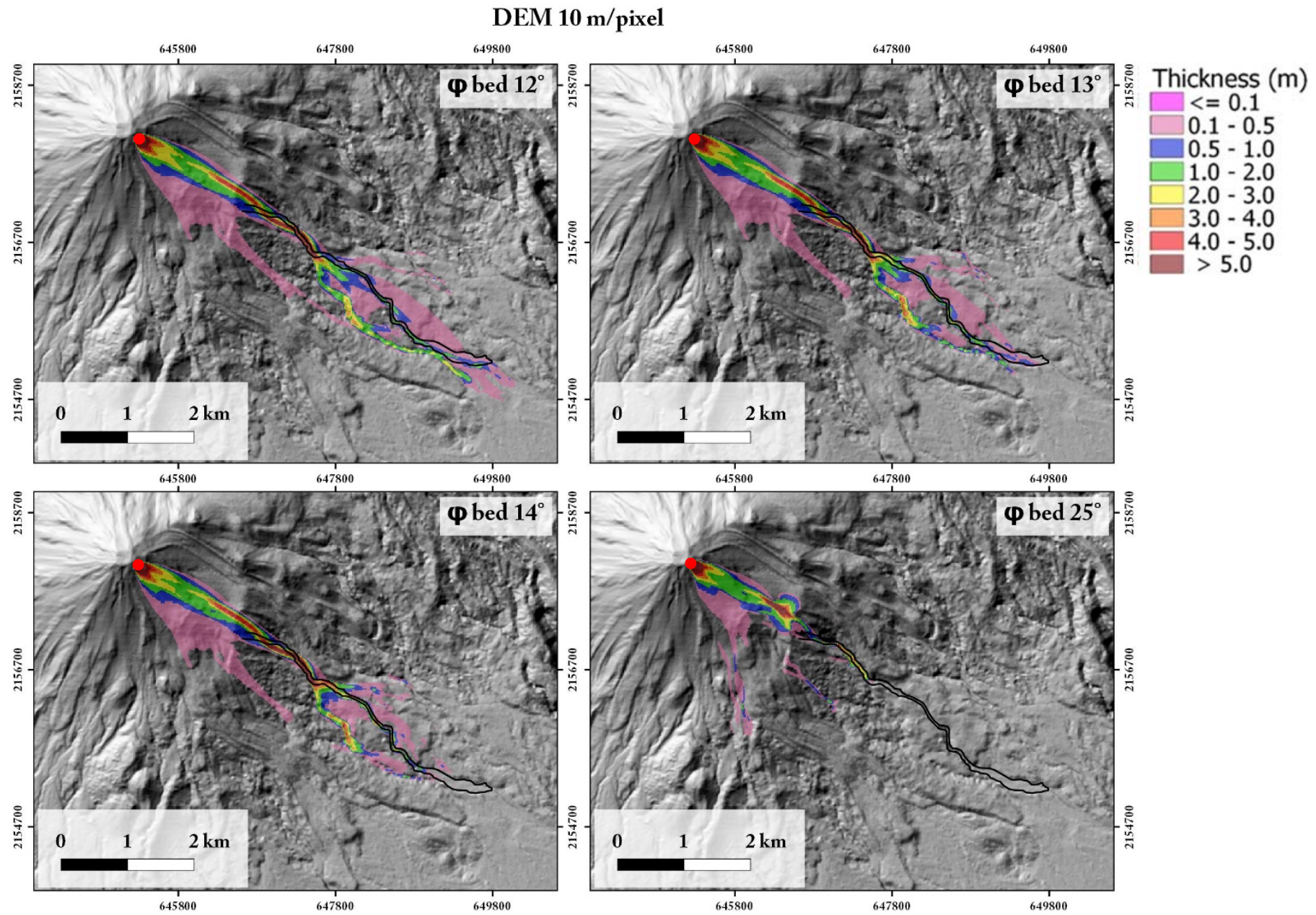

DEM $30 \mathrm{~m} /$ pixel
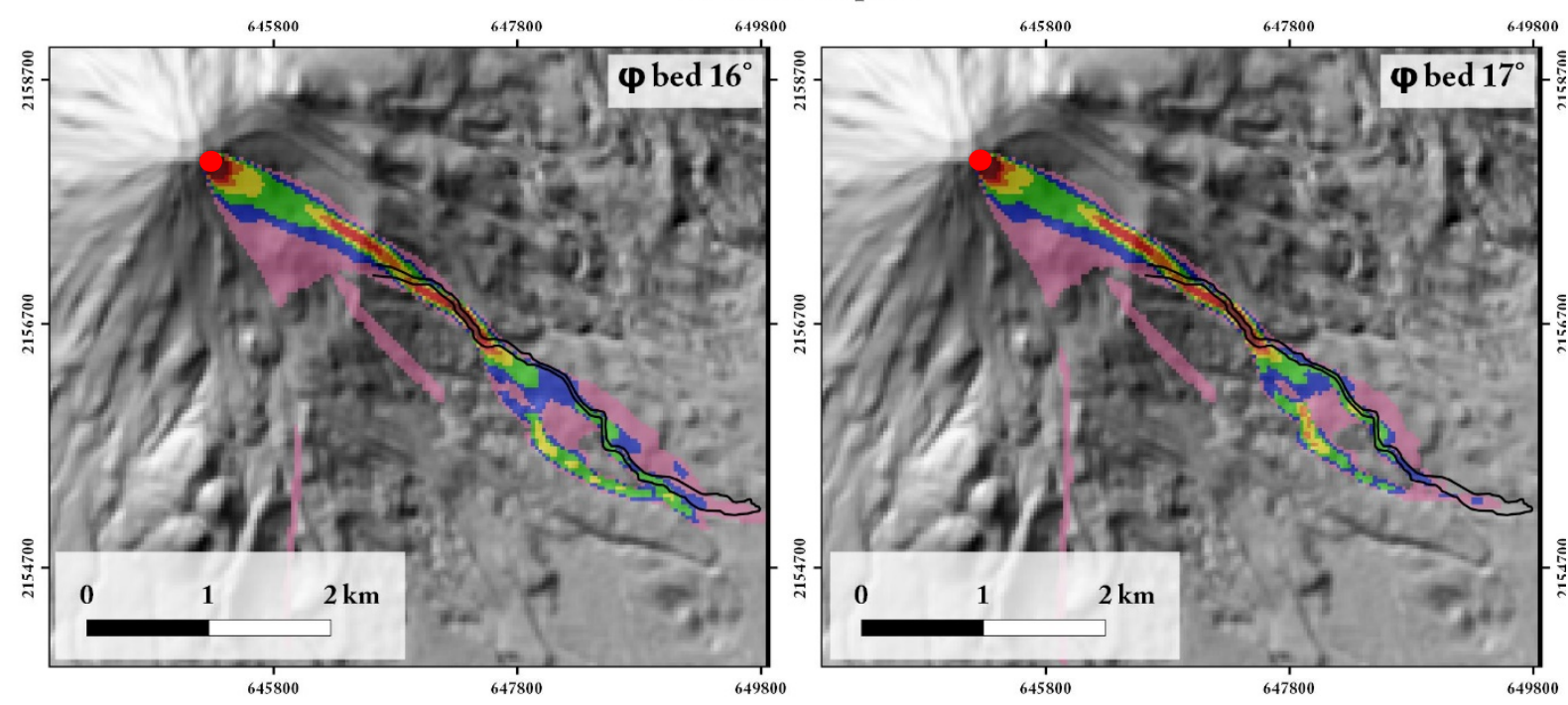

Figure 8. Distribution and flow thickness of BAF simulated with TITAN2D at changing basal friction angle, on different DEM (10 - $30 \mathrm{~m} /$ pixel resolution). The black line contours the real deposits. The simulated piles are marked with the red dots. 
The simulation shows an overbanking of the flow in proximity of the channel bend, which was not observed in the field. The flow splitting causes an overestimation of the deposit area.

The optimal $\varphi_{\text {bed }}$ slightly differs from a basal friction angle of $12^{\circ}$ obtained by Sulpizio et al. (2010), who performed the numerical simulations on a DEM with $5 \mathrm{~m} /$ pixel horizontal resolution. This suggests a relationship between DEM resolution and optimal $\varphi_{\text {bed }}$ (Capra et al., 2011), which was verified by us by means additional simulations on a DEM with $30 \mathrm{~m} /$ pixel horizontal resolution. $\varphi_{\text {bed }}$ of $16^{\circ}$ provided the best fit between simulated and observed BAF, which resulted in a simulated runout $1.7 \%$ greater than the real one (Fig. 8).

The overbanking flows observed on DEMs with 10 and $30 \mathrm{~m} /$ pixel horizontal resolution, are more extensive then simulations carried out by Sulpizio et al. (2010), highlighting again the dependence of results on DEM precision.

Finally, we simulated the BAF with $\varphi_{\text {bed }}$ obtained from the relationship of Figure $6\left(25^{\circ}\right)$, using a value of the SAR of 0.34 (Fig. 8). The simulation was performed on DEM with $10 \mathrm{~m} /$ pixel horizontal resolution.

The simulation with a high basal friction angle resulted in a runout $49 \%$ shorter than the real one. The distal part of simulated BAF shows flow thinner than the simulations with smaller $\varphi_{\text {bed }}$ and simulations on DEM with $30 \mathrm{~m} /$ pixel horizontal resolution. The premature flow stoppage and the lower flow thickness are due to the large $\varphi_{\text {bed }}$, which results in a mass excess close to the summit part of the ravines, in proximity of the first break in slope.

\subsection{Simulations of the wet case: volcaniclastic flows of the 5-6 $6^{\text {th }}$ May 1998 of Sarno}

The volcaniclastic flows of the $5-6^{\text {th }}$ May 1998 of Sarno were simulated using both two-phases TITAN2D and FLO2D codes. The volcaniclastic deposits from selected drainage basins were redrawn using QGIS software (http://qgis.osgeo.org) based on the map of Zanchetta et al. (2004) (Fig. 3), and used to compare real and simulated inundated areas.

The sediment concentration, volume and peak discharge data for flows from different drainage basins were taken from Zanchetta et al. (2004) are shown in Table A.1. Wet granular flows with a solid volume fraction of 0.41 can be classified as hyperconcentrated flows. 


\subsubsection{Two-phases TITAN2D numerical simulations}

The model requires the solid volume fraction of the flow, set to 0.41 . Simulations were performed on a DEM with $5 \mathrm{~m} /$ pixel horizontal resolution. Because the volumes of Sarno events were significantly changed by bulking processes during flow (Zanchetta et al., 2004), we run the simulations using two different geometries of the initial pile (Fig. 9). This allowed to take into account the effect of the pile geometry on the model predictions. The first simulation was made assigning the whole volume to a single pile, while the second was carried out using four piles distributed along the Ep_1 drainage basin, mirroring bulking processes along all the channelized flow path (Fig. 9). Because the value of $\varphi_{\text {bed }}$ is unknown, we set it at $26^{\circ}$ using the experimental regression line of Figure 6 with a value of the SAR of 0.42 . 

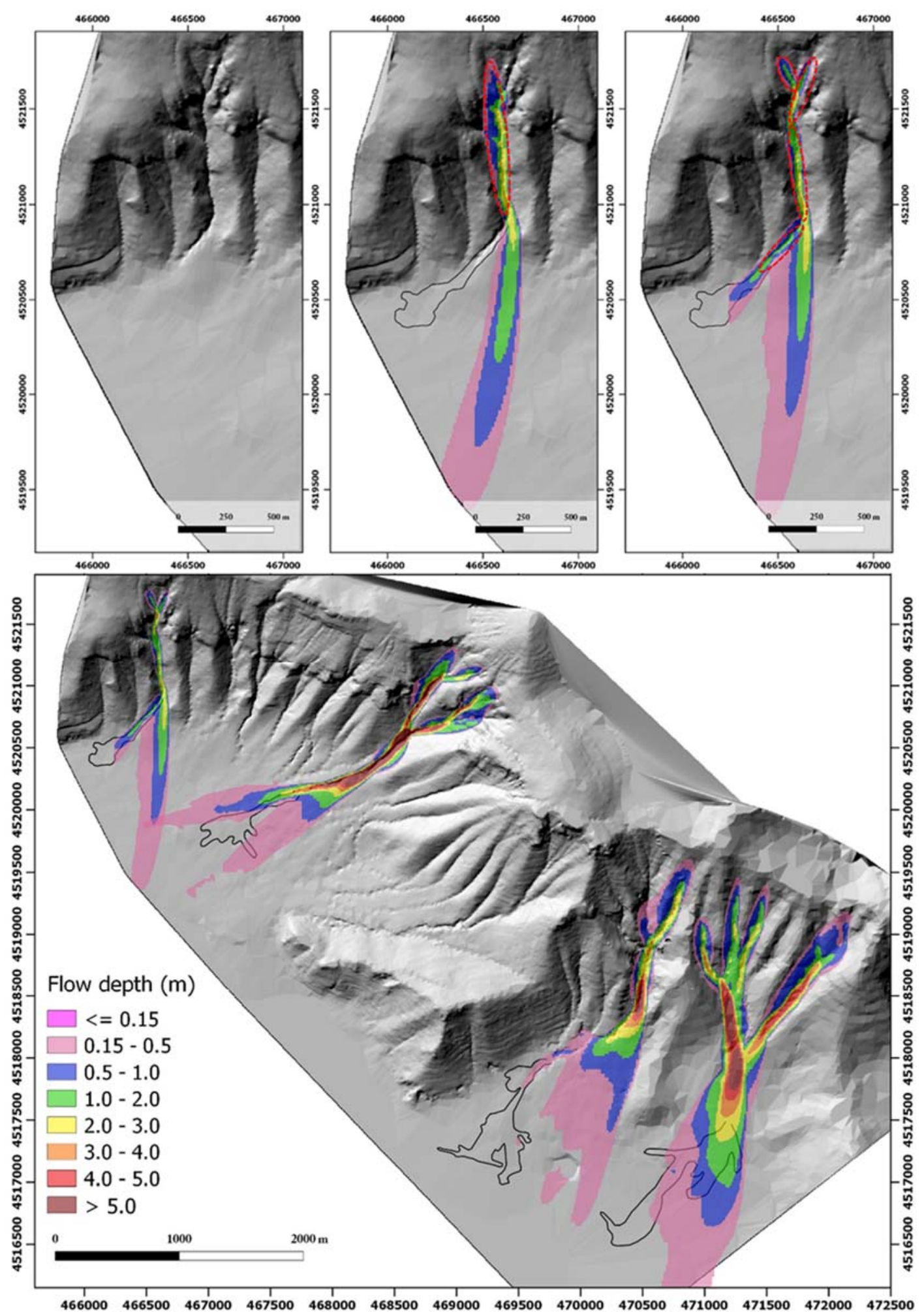

Figure 9. Inundation areas and flow thickness of flows simulated with two-phases TITAN2D. Top left the shaded relief of the Ep_1 basin. Middle, single pile simulation. Right, simulations with four piles distributed along the basin. Bottom, results for Ep_1, Ep_5, Lav_1 and Lav_2 events. The black line contours the deposit of the real flow. The simulated piles are marked with the dotted red line.

Both simulations show a deviation of the simulated flow path from real ones in proximity of the channel bend as seen for Colima case (Fig. 8). The simulation with distributed piles shows a 
secondary deposit branch that partially resemble the real deposits, which we attribute to the position of the lowermost pile beyond the channel bend. Both simulations generate an overestimation of runout (62\%; Table 2 ) and deposit area.

The simulated flows show maximum average velocities of $12-18 \mathrm{~m} \mathrm{~s}^{-1}$, with the highest velocities obtained from the simulation with a single pile. The velocity range is in the order of that calculated by Zanchetta et al. (2004) using empirical methods.

In order to evaluate the effective suitability of TITAN2D to simulate wet granular flows, we enlarged the simulations to some other drainage basins affected by the May 8-9, 1998 events in the Sarno area.

Because TITAN2D code does not allow to set more than one value of $\varphi_{\text {bed }}$ in a single simulation, the simulation of different events that interact during flow propagation is prevented. For these reasons, only the events from Ep_1, Ep_5, Lav_1 and Lav_2 drainage basins were simulated (Fig. 9). Input parameters, $R_{l}$ and maximum average velocities are listed in Table 2. It is worth noting that the $R_{l}$ values are reported in spite of the inundate areas do not coincide in most parts.

\begin{tabular}{cccccc}
\hline Event & $\boldsymbol{S A R}$ & $\boldsymbol{\varphi}_{\text {bed }}\left({ }^{\circ}\right)$ & $\boldsymbol{R}_{\boldsymbol{l}}(\%)$ & $\boldsymbol{v}_{\boldsymbol{m a x}}^{\text {sim }}(\boldsymbol{m} / \boldsymbol{s})$ & $\boldsymbol{v}_{\boldsymbol{m a x}}^{\text {obs }}(\boldsymbol{m} / \boldsymbol{s})$ \\
\hline Ep_1 & 0.42 & 26 & 162.3 & 15 & 13 \\
\hline Ep_5 & 0.45 & 26 & 112.2 & 13 & 18 \\
\hline Lav_1 & 0.51 & 27 & 100.2 & 12 & 15 \\
\hline Lav_2 & 0.50 & 27 & 121.0 & 14 & 20
\end{tabular}

Table 2. SAR, $\varphi_{\text {bed }}$, percent length ratio $\left(R_{l}\right)$, and average (simulated and observed) maximum velocities for the selected basins. SAR values for Episcopio_5, Lavorate_1 - 2 were taken from Zanchetta et al. (2004). $v_{\max }^{\operatorname{sim}}$ and $v_{\text {max }}^{\text {obs }}$ state for simulated and observed maximum velocties, respectively.

The simulated velocities are generally lower but in the same order of magnitude of the calculated ones (Zanchetta et al., 2004). The simulated runouts are in good agreement with the real ones (except for Ep_1), but they fail in replicating the real inundated areas. The Ep_1, Ep_5 and Lav_1 simulations show overbanking and splitting of the flow in proximity of the breaks in slope and channel bends. These generate overestimation of inundated areas and flow paths divergence from the observed ones. 


\subsubsection{FLO2D numerical simulations}

As already anticipated, FLO2D code needs a hydrograph as input. In areas without rain gauges and meteorological stations, it is difficult to assess an accurate hydrograph. For our simulations, the peak discharge and the sediment volume fraction obtained by Zanchetta et al. (2004) were used to reconstruct the inflow hydrograph, with a simple triangular shape (Fairchild 1987; Caruso and Pareschi 1993, and Iverson et al. 1998), with the left and right side of the triangle representing the waxing and waning stages of the flow, respectively (Caballero et al. 2016).

Manning- $n$ values were calculated with the method of Phillips and Tadayon (2006), taking into account only channel characteristics.

The rheological parameters $\alpha$ and $\beta$ were taken from the table of O'Brien and Julien (1988) for a sediment concentration value of 0.41 (Aspen Mine Fill values: $\alpha_{1}=0.128, \beta_{1}=12, \alpha_{2}=0.0473$ and $\left.\beta_{2}=21.1\right)$.

The laminar flow resistance was set to 2000 according to the values suggested in the FLO2D user guide. A limiting Froude number of 0.9 was set in agreement with the absence of sedimentary structures like cross-stratification and dunes, which are typically developed in a supercritical flow regime. Furthermore, supercritical flows in the debris flows are suppressed by the heavy load of transported sediment (e.g. Iverson, 1997; Caballero and Capra, 2014).

Simulated and observed deposits were quantitatively compared using percent length ratio $R_{l}$, Jaccard similarity coefficient $R_{j}$, flow thickness $T$, flow velocity $v$ and dynamic pressure $P_{d}$. The Jaccard similarity coefficient $R_{j}$ is defined as:

$$
R_{j}=\left|\frac{A_{o b s} \cap A_{\text {sim }}}{A_{\text {obs }} \cup A_{\text {sim }}}\right| \times 100=\frac{T P}{T P+F N+F P} \times 100
$$

$A_{\text {obs }} \cap A_{\text {sim }}$ is the areas inundated by both observed and simulated flows and is the true positive (TP). Areas inundated by only the simulated flows is the false positive (FP). Area inundated by only the observed flows is the false negative (FN).

The Jaccard similarity coefficient $R_{j}$ compares the lateral spreading of the observed and simulated inundated areas. A value of $R_{j}=1$ is a perfect match between real events and simulations. 
FLO2D can simulate interacting flows, therefore numerical simulations were performed on all the basins of the study area (Ep_1 - 7, Lav_1 - 2; Fig. 11). The calculated evaluation parameters and simulated/observed areas are reported in the Table 3, while the TP, FP and FN areas are shown in the Figure 10. The Ep_2 - 4 and the Ep_6-7 events, were simulated together because each event interacted with the others, modifying deposit area and flow thickness.

\begin{tabular}{lcccc}
\hline Flow & $\boldsymbol{R}_{\boldsymbol{l}}$ & $\boldsymbol{R}_{\boldsymbol{j}}$ & Observed Area $\left(\mathbf{m}^{2}\right)$ & Simulated Area $\left(\mathbf{m}^{2}\right)$ \\
\hline Ep_1 & $91.4 \%$ & $70.0 \%$ & 66193.7 & 55767.4 \\
Ep_2-3-4 & $166.1 \%$ & $60.2 \%$ & 324379.3 & 391087.8 \\
Ep_5 & $83.0 \%$ & $35.3 \%$ & 82127.5 & 112228.6 \\
Ep_6-7 & $120.9 \%$ & $58.6 \%$ & 289695.6 & 369959.8 \\
Lav_1 & $51.7 \%$ & $11.1 \%$ & 209384.0 & 60617.1 \\
Lav_2 & $66.2 \%$ & $20.2 \%$ & 319749.7 & 243008.2
\end{tabular}

Table 3. Evaluation parameters for FLO2D results.

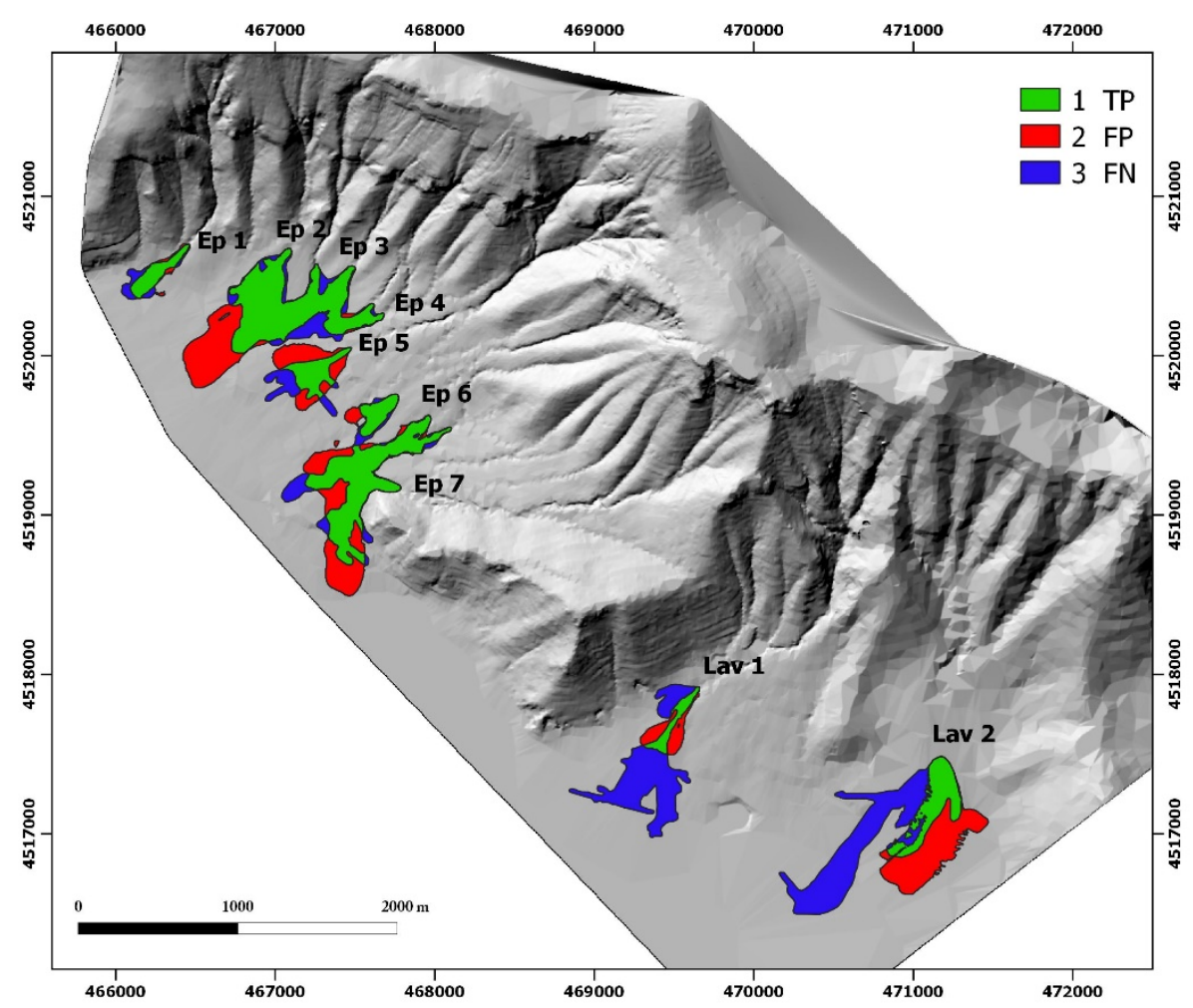

Figure 10. In green the overlapping areas between the real and simulated flows (TP), in red the overestimated areas (FP) and in blue the underestimated areas (FN).

The simulated runout of Ep_1 event shows an excellent correlation with the real deposit. The simulated runout and deposit area of events Ep_2, Ep_3 and Ep_4 are higher than the real ones. The comparing parameters indicate a simulated runout $66 \%$ larger than the real one and a 
consequent high lateral spread $\left(R_{j}=60.2 \%\right)$. The Ep 5 event shows a good correlation with the runout and deposit area of the real one. The Jaccard similarity coefficient with a value of $R_{j}=35 \%$ suggests a higher lateral spreading for the simulated flow (see Fig. 10, Ep_5). The events Ep_6 and Ep_7 show a general good correlation between simulated and real data. The runout is $20 \%$ longer than the real one and a simulated lateral spreading slightly higher than the observed hyperconcentrated flows. The events Lav_1 and Lav_2 show the worst results, both for $R_{l}$ and for $R_{j}$ (see Table 3). These latter simulations show how the real flows diverge from the local topography following the not usual stream drainage.

FLO2D results are shown in the following figures for the final floodplain flow depth, velocities, max flow depth and hydrostatic pressure (Fig. 11). 

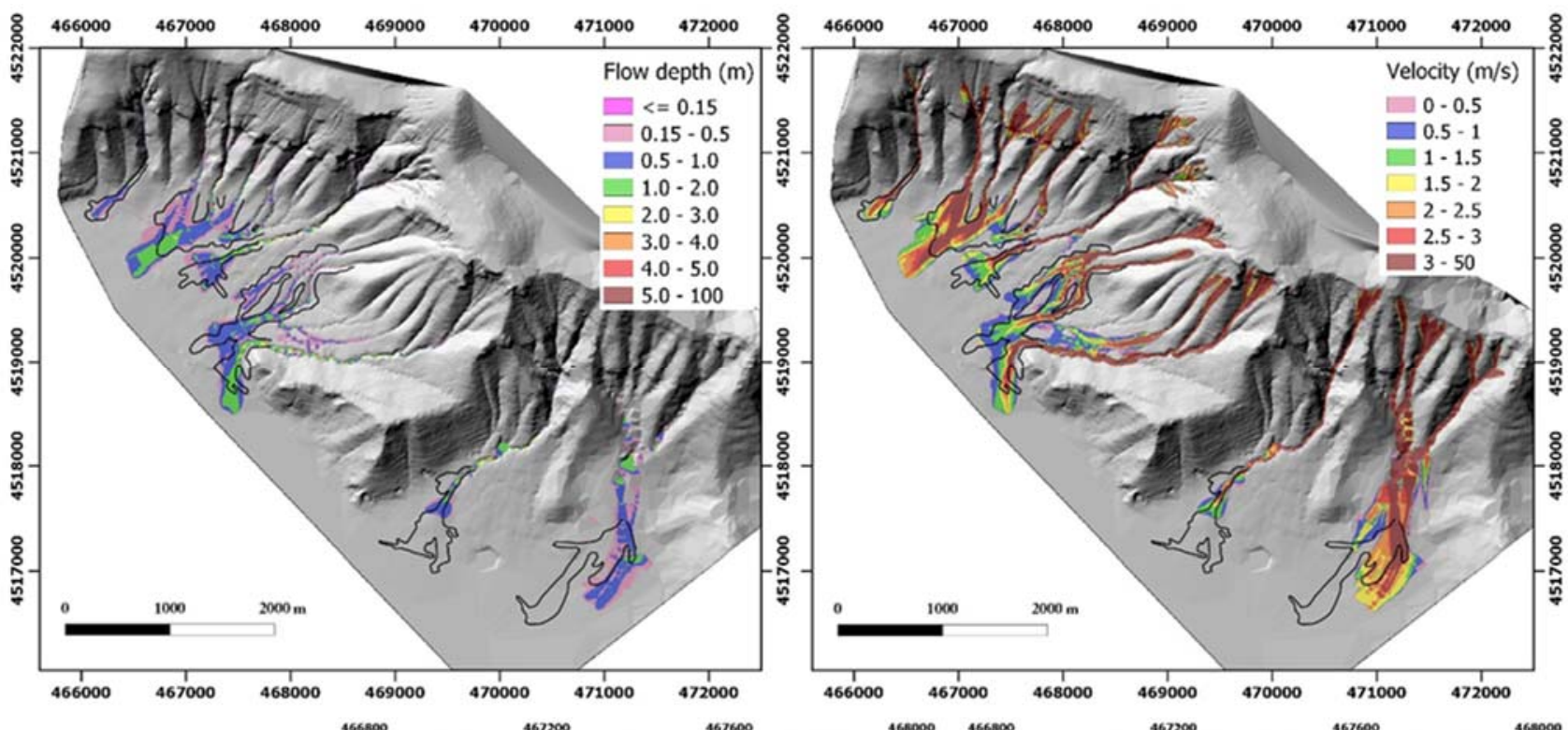

Max flow depth (m)

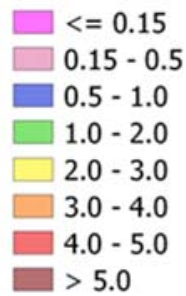

Static pressure $(\mathrm{Pa})$
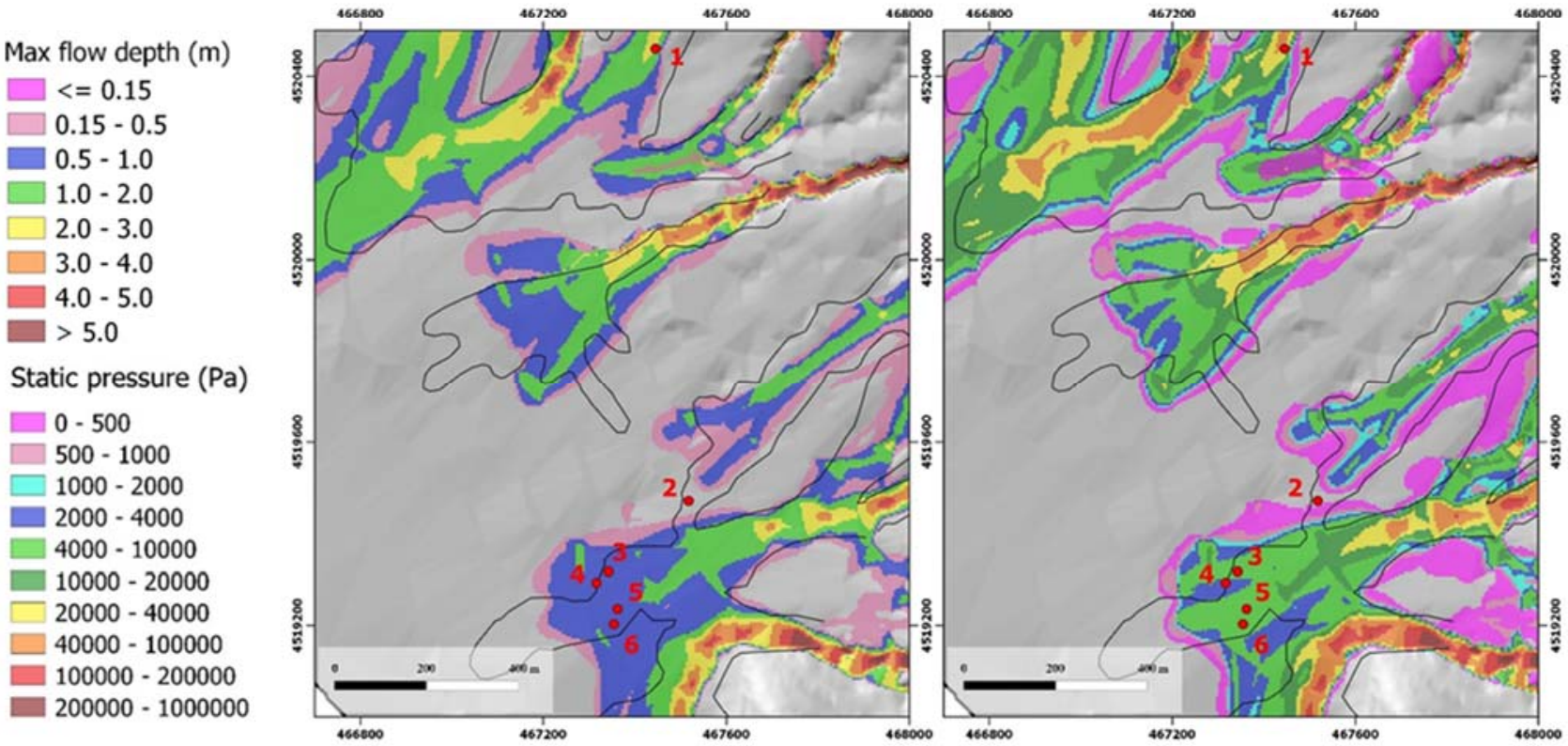

Figure 11. At the top, final floodplain flow thickness and velocities of simulated flows. At the bottom, max flow depth and static pressures of simulated flows in Episcopio area. The black line contours the deposit of the real flows. The red circles indicate the locations where max flow depth and pressures measures were collected by Zanchetta et al. (2004) (see Table 4).

\begin{tabular}{ccccccc}
\hline \multicolumn{5}{c}{ Observed data } & \multicolumn{5}{c}{ Simulated data } \\
\hline Point & $\boldsymbol{P}_{\boldsymbol{h y}}(\mathbf{k P a})$ & $\boldsymbol{P}_{\boldsymbol{d} \boldsymbol{y}}(\mathrm{kPa})$ & Max flow depth $(\mathbf{m})$ & $\boldsymbol{P}_{\boldsymbol{h} \boldsymbol{y}}(\mathbf{k P a})$ & $\boldsymbol{P}_{\boldsymbol{d y}}(\mathbf{k P a})$ & Max flow depth (m) \\
1 & 33.00 & 140.00 & 3.80 & 48.00 & 187.82 & 2.43 \\
2 & 28.00 & 60.00 & 3.30 & - & - & - \\
3 & 14.00 & 20.00 & 1.60 & 5.91 & 4.74 & 0.91 \\
4 & 14.00 & 20.00 & 1.60 & 2.55 & 1.06 & 0.64 \\
5 & 14.00 & 20.00 & 1.60 & 6.11 & 4.99 & 0.86 \\
6 & 14.00 & 20.00 & 1.60 & 4.75 & 2.61 & 0.77
\end{tabular}

Table 4. Comparison between the observed and simulated values, at the same position. $\mathrm{P}_{\text {hy }}=$ hydrostatic or static pressure; $P_{d y}=$ dynamic pressure. 
The simulated velocities range between $2 \mathrm{~m} \mathrm{~s}^{-1}$ and $20 \mathrm{~m} \mathrm{~s}^{-1}$, in good agreement with those calculated by Zanchetta et al. (2004) $\left(3-18 \mathrm{~m} \mathrm{~s}^{-1}\right)$.

The measured flow heights in Episcopio area vary from a maximum of ca. $3.8 \mathrm{~m}$ to a minimum of $1.6 \mathrm{~m}$ near the deposit front (Zanchetta et al., 2004), while the simulated flow depths range from $2.5 \mathrm{~m}$ to $0.60 \mathrm{~m}$. The simulated static pressures and dynamic pressures are slightly lower with respect to those calculated by Zanchetta et al. (2004). The simulated dynamic component of the total pressure is lightly lower than the static component (Table 4).

\section{Discussion}

The application of TITAN2D and FLO2D to different case studies, highlighted some pro and cons of these two largely used numerical model for simulating the motion of dry and wet granular flows. Emerges that the most prominent points of discussion include the set-up of reliable $\varphi_{\text {bed }}$ and pile location (single vs distributed) in TITAN2D, DEM accuracy (TITAN2D and FLO2D), and comparison of results from two-phases TITAN2D and FLO2D.

\subsection{Analysis of $\varphi_{\text {bed }}$ and pile location in TITAN2D simulations}

We applied TITAN2D to all the case studies, being this code (and its latest two-phases development) largely applied to concentrated pyroclastic density currents (BAFs) and wet granular flows. It was used both to replicate past events (Sheridan et al. 2005; Charbonnier and Gertisser, 2009; Sulpizio et al., 2010) or to produce hazard maps (Charbonnier and Gertisser, 2012).

The simulation of past events is the less problematic, because some crucial input parameters can be adjusted until the target parameters (e.g. real runout) are matched by the simulations. This can be made by using different pile collapse configuration in the source area and/or varying $\varphi_{\text {bed }}$ of the flowing material. $\varphi_{\text {bed }}$ was proved to be the most sensitive parameter for running TITAN2D, being a single constant value applied to the whole computational domain. This usually results in 
unrealistic values of $\varphi_{\text {bed }}$ used to match simulated and real deposits, especially in flow paths with varying channel slopes and morphologies (Stinton et al., 2004). In some cases, it obliges to use artifacts to match actual and simulated deposits, such as "stop-and-go" simulation runs in which the flow is stopped, the bed friction value is changed and then the simulation is restarted as a new run (i.e. Merapi case, Charbonnier and Gertisser, 2009).

The problem of bed friction angle in TITAN2D cannot be easily solved since $\varphi_{\text {bed }}$ is affected by several parameters like the basal surface roughness, flow thickness, grainsize distribution, topography, channel irregularity, presence of obstacles or hydraulic jumps, among others. These parameters vary in space and time, in some case within the flow itself. Consequently, it is almost impossible to set the right $\varphi_{\text {bed }}$ a priori for the whole computational domain, particularly when preliminary information on the past deposit are not available. In view of the foregoing, $\varphi_{\text {bed }}$ used in TITAN2D represents an average value of all the parameters listed above, which strongly influence the simulations results.

Another important point is that the bed friction angle is sensitive to the SAR at break in slope, as demonstrated by the large-scale experiment case study (Fig. 4). It is evident how the TITAN2D simulations needs an increasing value of the bed friction angle at increasing SAR (Fig. 4). The passage over the break in slope is one of the main parameters that influence the dynamics of volcanic granular flows (Denlinger and Iverson, 2001; Iverson et al., 2004; Zanchetta et al., 2004; Sulpizio and Dellino, 2008; Sulpizio et al., 2014), because the local curvature at the break in slope induces an increase of the velocity components perpendicular to the surface and a thickening of the flow (Denlinger and Iverson, 2001). It has been demonstrated by laboratory experiments how the runout is positively correlated to the SAR, being longer at increasing SAR (i.e. higher local curvatures radii; Sulpizio et al., 2016). This should implies a lowering of the bed friction angle, which is exactly the opposite we observed with TITAN2D runs (Fig. 4). Indeed, higher $\phi_{b e d}$ are needed to stop faster flows caused by greater SAR at the break in slopes.

For the Colima case, the best $\varphi_{\text {bed }}$ was $13^{\circ}$ for a DEM resolution of $10 \mathrm{~m} / \mathrm{pixel}$, and $16^{\circ}$ for a DEM resolution of $30 \mathrm{~m} /$ pixel. A $\varphi_{\text {bed }}$ of $12^{\circ}$ on a $5 \mathrm{~m} /$ pixel DEM was obtained by Sulpizio et al. (2010). This suggests that higher resolution DEM require lower basal friction angle to better fit the real runouts. The dependence of best $\varphi_{\text {bed }}$ to the DEM resolution may be due to topographic smoothing effect of a lower resolution DEM, which emphasizes the role of SAR in $\varphi_{\text {bed }}$ variations. 
We gained some further interesting insights about a first order relationship between $\phi_{\text {bed }}$ and SAR (for SAR > 0) using the BAF at Colima Volcano and the events in the Sarno area (Fig. 8 ad 9). When selecting $\phi_{\text {bed }}$ values from the relationship of Figure 6 for the different Sarno basins, the simulated runout satisfactorily match the real ones (except for Ep_1 event simulation), although the flow paths totally diverge from the real ones. On the contrary, the selected $\phi_{\text {bed }}$ for the BAF produced an underestimated runout $\left(R_{l}=51 \%\right)$ and a mas excess close the first break in slope. These results may indicate that the obtained $\phi_{\text {bed }}$ VS SAR relationship works for basins with simple geometry of the main channel (i.e. only one break in slope, almost rectilinear channel, small catchment area), while it is ineffective for long channels with several break in slopes and complex channel morphology (i.e. the Colima case).

SAR $=0$ was excluded from the relationship above mentioned because of the unrealistic shape of the simulated flow in proximity of the channel exit (Fig. 4). This unrealistic shape could be explained by the abrupt break in slope, which reflects in increase of velocity component normal to the surface coupled with the wall effect at the channel exit. Analysing Eq. 8 it is evident how the shear stress $\tau_{\mathrm{xz}}$ critically depends on the term $U / r_{x} g_{z}$, which expresses the partition of stress as function of local curvature radius $r_{\mathrm{x}}$. In particular, $\tau_{\mathrm{xz}}$ has an hyperbolic dependence on $r_{\mathrm{x}}$, which means that for low values of $r_{x}$ the shear stress shows an asymptotic increase to very high values. This is an effect that is poorly accountable by computational point of view. Changing the spreading box slope increases the curvature radius at break in slope and the tangential component of the velocity, which is probably better simulated by numerical code with a better match between simulated and real data (Fig. 4).

Another crucial issue in setting input parameters up when using TITAN2D is the choice of single vs. distributed pile of starting material. The single pile resembles the triggering mechanism of the concentrated flow when the collapse is restricted to a small area, like in the case of collapse of the dome that triggered the 2005 BAFs at Colima. The distributed choice better describes bulking processes along the flow path or flow mass increase due arrivals from tributary channels, like in the case of Sarno events. The choice of single or distributed pile location is not trivial, because the single case is expected to produce higher flow velocity and runout, as demonstrated during laboratory experiments (Iverson et al., 2010; Sulpizio et al., 2016). The higher momentum of the flow for the single pile set up may produce overflows at channel bends, which is one of the main limitations observed when simulating the Colima and Sarno events with TITAN2D (Figs. 8 and 9). 
The overbanking effect is not only due to higher momentum of the flowing mixture, but also relates with DEM precision, an issue discussed in the following paragraph.

\subsection{Sensitivity to DEM resolution}

The importance of the DEM resolution on outputs of numerical models of gravity flows has been explored in different studies in the past (e.g. Stevens et al. 2003; Pitman et al. 2003; Capra et al. 2011). The DEM resolution is of primary importance for reliable replications of simulated flow paths and inundated areas. This is even more prominent when numerical codes are applied in predictive way, as an example for individuating flow velocity, flow depths and inundated zones in areas prone to generate hazardous volcaniclastic flows and/or concentrated PDCs.

The importance of DEM resolution on numerical code outputs is also confirmed by our case studies, with a substantial difference between TITAN2D and FLO2D codes. Upon analysing the results of the application of TITAN2D and FLO2D to the Ep_1 event in the Sarno area (Fig. 9), it is evident how the TITAN2D simulations do not follow the real channel path diverging in proximity of the channel bend. This is not the case of the FLO2D simulation, which better replicates the real deposit and flow path. It can be concluded that, by using a DEM resolution of $5 \mathrm{~m}$, FLO2D better resolves the topographic constraint to the flow path with respect to the TITAN2D. This is probably due to the fact that FLO2D uses as input parameter a hydrograph, while TITAN2D initialized the flow by dropping a pile of material, which has to be placed somewhere in the drainage basin.

As a consequence, the simulations of granular flows for predictive purposes (i.e. hazard zonation) using TITAN2D code need careful consideration even when applied to DEM of intermediate-high resolution.

\subsection{Comparison of results from two-phases TITAN2D and FLO2D}

The events of May 5-6, 1998 at Sarno were simulated with FLO2D and two-phases TITAN2D codes using the same DEM precision ( $5 \mathrm{~m} /$ pixel horizontal resolution). This allows some discussion on different results obtained using the two codes. 
FLO2D results show a general better match between simulated and observed runouts and inundated areas with respect to two-phases TITAN2D simulations. In fact, the predicted FLO2D inundated areas have higher Jaccard similarity coefficient $\left(R_{j}\right)$ and similar runouts with respect to two-phases TITAN2D simulations. This means that FLO2D better accommodates the flowing material to the available digital terrain, probably because the use of the hydrograph distributes the total volume of the moving flow over a sufficient time for containing it within the digital channel. On the contrary, the momentum-based description of the flow motion in TITAN2D is less easy to be confined within channels, especially at channel bends. In addition, the arrival of most of the flow volume in short time produces filling of the digital channel and overflow of the upper part of the moving mixture. This effect is quite visible in all the two-phases TITAN2D simulations in the Sarno area, probably enhanced by the poorly incised channels in the alluvial fan area, not accurately captured by the 5 $\mathrm{m} /$ pixel DEM resolution. Furthermore, the two-phases TITAN2D, calculating buoyancy effect coupled with pore pressure, generates greatly fluidized wet granular flows as in Sarno case. Even for the more satisfactory results of the FLO2D simulations the DEM inaccuracy produces second order differences in inundated area (e.g. Ep_2 - 7 basins; Fig. 10 and 11). Some other processes like partial flow stopping against obstacles (houses, infrastructures) and re-channelizing along the main streets of Episcopio village influenced the real inundation paths in the depositional area. The absence of urban structures on the DEM accounts for these differences, which also reflect on the simulated dynamic and static pressures that are slightly lower than those empirically calculated (Zanchetta et al., 2004; Fig. 10 and 11).

Another discussion point regards the rheological model and parameters, which regulate the flow internal behaviour and the flow-bottom surface interaction. TITAN2D takes into account only a Coulomb-type friction term for internal and basal friction, whereas FLO2D thanks to the shear stress relationship (Eq. 13), takes also the viscous and dispersive contribution into account (together with the Manning roughness coefficient accounting for the channel's resistance to flow), which are dominant in this type of flows. Furthermore, there is no guarantee that the used rheological parameters $\alpha$ and $\beta$ are appropriate for the Sarno wet granular flows, because these parameters should be measured in laboratory by means of a rheometer. This aspect coupled with a different problem initialization (inflow hydrograph vs piles) proves to be crucial in a better match between simulated and real flows. 


\section{Conclusion}

In this work we tested the TITAN2D (including the two-phases model) and FLO2D against natural and laboratory wet and dry volcanic granular flows.

TITAN2D is relative easy to use, because it requires few input parameters to be set up. On the other hand, our results confirm the critical influence of the basal friction angle, which is fixed for each simulation run and is related to physical characteristics of the sliding material, substratum and to the features directly linked to DEM and its resolution (local topographic complexities, channel irregularity, obstacles etc.). By means of large-scale experiments, we highlighted how $\varphi_{\text {bed }}$ critically depends on the slope-angle ratio SAR, but we did not investigate on parameters like surface roughness, particles properties and channel tortuosity.

Another critical input parameter of TITAN2D is the location of the collapsing pile. By analysing the simulated Sarno events it emerged how the release of all the material from a single pile produced the worst results with respect to simulations with the material released from simultaneous piles. This points out how the occurrence of bulking vs. single collapse mechanism have to be carefully assessed before running the simulations, especially if used for future event forecasting. A significant improvement would descend from the implementation of a dynamic basal friction angle law and more sophisticated flow-initiation models. In fact, TITAN2D shows the best results for events characterized by small volumes with simple aerial distributions that can be easily approximated by a collapse of a pile (like the summit dome at Colima).

FLO2D demonstrated better results when applied to the Sarno events with respect to TITAN2D. This is mainly due to the use of a hydrograph that better distributes the flowing volume over time, allowing better confinement of the moving flow within the digital channels (using a DEM of $5 \mathrm{~m} / \mathrm{pixel}$ horizontal resolution). However, the hydrograph estimation could be difficult for areas not hydrologically monitored or for replicating past events for which flow parameters are not available. The shear stress calculation that includes contribution from five shear stress terms (cohesive, MohrCoulomb, viscous, turbulent and collisional shear stress) replicates fundamental processes taking place in volcaniclastic flows, such as dispersive stress due to the particles collisions and cohesiveness of flows rich in fine sediment.

On the other hand, the selection of FLO2D parameters is more complicated than in TITAN2D, particularly concerning the parameters of the rheological model $(\alpha$ and $\beta$ ) that depend on the sediment concentration and type. Tabulated values are available for some sediments, however very 
little data are available for volcanic material and ideally these parameters should be quantified by means of laboratory rheological measurements.

Both TITAN2D and FLO2D, do not account for bulking of a volcaniclastic flows, and this is a major limitation of both codes. Finally, the DEM resolution remains a key parameter that controls the dynamics and the evolution of the simulated flows.

This work is intended to represent a preliminary consult for everyone approaching the TITAN2D and FLO2D models and the shallow-water approach to the geophysical flows. Furthermore, the highlighted limitations represent a starting point for researching new approaches describing the dynamics of volcanic granular mixtures in order to improve the capability to reproduce past events and predict potential future events, enhancing planning and mitigation strategies of the risk connected to volcanic granular flows.

Appendix A: Volumes and peak discharges of the lahars of the 5-6 $6^{\text {th }}$ May 1998 of Sarno

\begin{tabular}{lcc}
\hline Flow & Volume $\left(\mathrm{m}^{3}\right)$ & $\mathrm{Q}_{\mathrm{p}}(\mathrm{m} / \mathrm{s})$ \\
\hline Ep_1 & $36 \cdot 10^{3}$ & $0.6 \cdot 10^{3}$ \\
Ep_2 & $124 \cdot 10^{3}$ & $1.7 \cdot 10^{3}$ \\
Ep_3a & $101 \cdot 10^{3}$ & $1.5 \cdot 10^{3}$ \\
Ep_3b & $88 \cdot 10^{3}$ & $1.3 \cdot 10^{3}$ \\
Ep_4 & $53 \cdot 10^{3}$ & $0.9 \cdot 10^{3}$
\end{tabular}




$\begin{array}{lcc}\text { Ep_5 } & 158 \cdot 10^{3} & 2.1 \cdot 10^{3} \\ \text { Ep_6a } & 121 \cdot 10^{3} & 1.7 \cdot 10^{3} \\ \text { Ep_6b } & 73 \cdot 10^{3} & 1.1 \cdot 10^{3} \\ \text { Ep_7a } & 38 \cdot 10^{3} & 0.7 \cdot 10^{3} \\ \text { Ep_7b } & 253 \cdot 10^{3} & 3.2 \cdot 10^{3} \\ \text { Lav_1 } & 105 \cdot 10^{3} & 1.6 \cdot 10^{3} \\ \text { Lav_2 } & 275 \cdot 10^{3} & 3.4 \cdot 10^{3}\end{array}$

Table A.1. Lahars from different drainage basins with their volume and peak discharge (from Zanchetta et al., 2004).

\section{References}

Anderson, T. B., and R O Y Jackson. 1967. "A Fluid Mechanical Description of Fluidized Beds." Industrial \& Engineering Chemistry Fundamentals.

Bagnold, F.R.S. 1956. "Experiments on a Gravity-Free Dispersion of Large Solid Spheres in a Newtonian Fluid under Shear." Proceedings of the Royal Society of London A.

Barré de Saint-Venant, Adhémar Jean Claude. 1871. “Th\{é\}orie Du Mouvement Non Permanent Des Eaux, Avec Application Aux Crues Des Rivi\{è\}res et \{à\} I'introduction Des Mar\{é\}es Dans Leurs Lits." Comptes Rendus des s\{é\}ances de l'Acad\{é\}mie des Sciences.

Caballero, L., and L. Capra. 2014. "The Use of FLO2D Numerical Code in Lahar Hazard Evaluation at Popocatépetl Volcano: A 2001 Lahar Scenario." Natural Hazards and Earth System Sciences 14(12): 3345-55.

Caballero, L., L. Capra, and R. Vázquez. 2016. “Evaluating the Performance of FLO2D for Simulating Past Lahar Events at the Most Active Mexican Volcanoes :" : 179-89.

Calcaterra, D; Parise, M.; Palma, B.; Pelella, L. 2000. "Multiple Debris-Flow in Volcaniclastic Materials Mantling Carbonate Slopes." International Conference on Debris Flow Hazards Mitigation (January): 99-107.

Calcaterra, D., M. Parise, B. Palma, and L. Pelella. 1999. "The May 5th , 1998 , Landsliding Event in Campania ( Southern Italy ): Inventory of Slope Movements in the Quindici Area." (January).

Campbell, Charles S. 2006. “Granular Material Flows - An Overview." Powder Technology 162(3): 208-29.

Capra, L. et al. 2008. "Volcanic Hazard Zonation of the Nevado de Toluca Volcano, México." 
Journal of Volcanology and Geothermal Research 176(4): 469-84.

Capra, L., V. C. Manea, M. Manea, and G. Norini. 2011. "The Importance of Digital Elevation Model Resolution on Granular Flow Simulations: A Test Case for Colima Volcano Using TITAN2D Computational Routine." Natural Hazards 59(2): 665-80.

Caruso, P., and M. T. Pareschi. 1993. "Estimation of Lahar and Lahar-Runout Flow Hydrograph on Natural Beds." Environmental Geology.

Charbonnier, S. J. et al. 2018. "Modeling the October 2005 Lahars at Panabaj (Guatemala)." Bulletin of Volcanology 80(1).

Charbonnier, S. J., and R. Gertisser. 2009. "Numerical Simulations of Block-and-Ash Flows Using the Titan2D Flow Model: Examples from the 2006 Eruption of Merapi Volcano, Java, Indonesia." Bulletin of Volcanology.

- - . 2012. "Evaluation of Geophysical Mass Flow Models Using the 2006 Block-and-Ash Flows of Merapi Volcano, Java, Indonesia: Towards a Short-Term Hazard Assessment Tool." Journal of Volcanology and Geothermal Research 231-232: 87-108.

http://dx.doi.org/10.1016/j.jvolgeores.2012.02.015.

Chirico, G. B., P. Claps, F. Rossi, and P. Villani. 2000. “Hydrologic Conditions Leading To Initiation in The."

Costa, J. E. 1984. "Physical Geomorphology of Debris Flows." Developments and applications of geomorphology.

Cowan, W.L. 1956. "Estimating Hydraulic Roughness Coefficients." Agricultural Engineering,

Denlinger, Roger P., and Richard M. Iverson. 2001. "Flow of Variably Fluidized Granular Masses across Three-Dimensional Terrain: 2. Numerical Predictions and Experimental Tests." Journal of Geophysical Research: Solid Earth 106(B1): 553-66.

Fairchild, Lee H. 1987. "The Importance of Lahar Initiation Processes." GSA Reviews in Engineering Geology.

Friedrichs, K. O. 1948. "Waves on a Shallow Sloping Beach." Communications on Pure and Applied Mathematics.

Gavilanes-Ruiz, Juan Carlos et al. 2009. “Exploring the Factors That Influence the Perception of 
Risk: The Case of Volcán de Colima, Mexico." Journal of Volcanology and Geothermal Research.

Hutter, Kolumban, Klaus Jöhnk, Kolumban Hutter, and Klaus Jöhnk. 2004. "Introduction." In Continuum Methods of Physical Modeling,

Iverson, R. M., and J. W. Vallance. 2001. "New Views of Granular Mass Flows." Geology 29(2): 11518.

Iverson, Richard M. 1997. "The Physics of Debris Flows." Reviews of Geophysics.

Iverson, Richard M., and Roger P. Denlinger. 2001. "Flow of Variably Fluidized Granular Masses across Three-Dimensional Terrain: 1. Coulomb Mixture Theory." Journal of Geophysical Research: Solid Earth.

Iverson, Richard M., Matthew Logan, and Roger P. Denlinger. 2004. “Granular Avalanches across Irregular Three-Dimensional Terrain: 2. Experimental Tests." Journal of Geophysical Research: Earth Surface 109(F1): 1-16.

Iverson, Richard M., Steven P. Schilling, and James W. Vallance. 1998. “Objective Delineation of Lahar-Inundation Hazard Zones." Bulletin of the Geological Society of America 110(8): 972-84.

Jia, Yafei. 1990. "Minimum Froude Number and the Equilibrium of Alluvial Sand Rivers." Earth Surface Processes and Landforms.

Kelfoun, K., and T. H. Druitt. 2005. "Numerical Modeling of the Emplacement of Socompa Rock Avalanche, Chile." Journal of Geophysical Research: Solid Earth.

Liggett, James A. 1994. "Governing Equations for Free Surface Flows." In Computer Modeling of Free-Surface and Pressurized Flows,.

Luhr, James F., Carlos Navarro-Ochoa, and Ivan P. Savov. 2010. "Tephrochronology, Petrology and Geochemistry of Late-Holocene Pyroclastic Deposits from Volcán de Colima, Mexico." Journal of Volcanology and Geothermal Research.

Macías, José Luis et al. 2006. “Flujos Piroclásticos Asociados a La Actividad Explosiva Del Volcán de Colima y Perspectivas Futuras." Geos 25(3): 417-28.

O’Brien, J.S., and P.Y. Julien. 1988. “Abstract: Introduction.” Journal of Hydraulics Engineering 114(8): 877-87. 
O’Brien, J.S., P.Y. Julien, and W.T. Fullerton. 1993. "Two-Dimensional Water Flood and Mudflow Simulations." Sciences-New York 146(2): 139-46.

Pareschi, M. T. et al. 2000. "May 5, 1998, Debris Flows in Circum-Vesuvian Areas (Southern Italy): Insights for Hazard Assessment." Geology 28(7): 639-42.

Pareschi, M. T., R. Santacroce, R. Sulpizio, and G. Zanchetta. 2002. "Volcaniclastic Debris Flows in the Clanio Valley (Campania, Italy): Insights for the Assessment of Hazard Potential." Geomorphology 43(3-4): 219-31.

Patra, Abani K. et al. 2005. "Parallel Adaptive Numerical Simulation of Dry Avalanches over Natural Terrain." Journal of Volcanology and Geothermal Research 139(1-2): 1-21.

Phillips, Jeff V., and Saeid Tadayon. 2006. "Selection of Manning' s Roughness Coefficient for Natural and Constructed Vegetated and Non- Vegetated Channels, and Vegetation Maintenance Plan Guidelines for Vegetated Channels in Central Arizona." Geological Survey Scientific Investigations Report 2006-5108: 41.

Pierson, Thomas C., Richard J. Janda, Jean Claude Thouret, and Carlos A. Borrero. 1990. "Perturbation and Melting of Snow and Ice by the 13 November 1985 Eruption of Nevado Del Ruiz, Colombia, and Consequent Mobilization, Flow and Deposition of Lahars." Journal of Volcanology and Geothermal Research 41(1-4): 17-66.

Pitman, E. B., and L. Le. 2005. "A Two-Fluid Model for Avalanche and Debris Flows." Philosophical Transactions of the Royal Society A: Mathematical, Physical and Engineering Sciences 363(1832): 1573-1601.

Pitman, E. Bruce et al. 2003. "Computing Granular Avalanches and Landslides." Physics of Fluids.

Del Prete, M., F. M. Guadagno, and A. B. Hawkins. 1998. "Preliminary Report on the Landslides of 5 May 1998, Campania, Southern Italy." Bulletin of Engineering Geology and the Environment 57(2): 113-29.

Rankine, M.W.J. 1856. "On the Stability of Loose Earth." The Royal Society of London.

RM Iverson. 1997. "The Physics of Debris Flows." 《Reviews of Geophysics》35(3): 245-96.

Sarocchi, D., R. Sulpizio, J. L. Macías, and R. Saucedo. 2011. "The 17 July 1999 Block-and-Ash Flow (BAF) at Colima Volcano: New Insights on Volcanic Granular Flows from Textural Analysis." 
Journal of Volcanology and Geothermal Research.

Saucedo, R. et al. 2005. "Modeling of Pyroclastic Flows of Colima Volcano, Mexico: Implications for Hazard Assessment." Journal of Volcanology and Geothermal Research.

Savage, S. B., and K. Hutter. 1989. "The Motion of a Finite Mass of Granular Material down a Rough Incline." Journal of Fluid Mechanics 199(2697): 177-215.

Savage, S.B., and K. Hutter. 1991. "The Dynamics of Avalanches of Granular Materials from Initiation to Runout. Part I: Analysis." Acta Mechanica 86(1): 201-23. http://www.springerlink.com/index/10.1007/BF01176820.

Scott, Kevin M. 1988. "Origins, Behavior, and Sedimentology of Lahars and Lahar-Runout Flows in the Toutle-Cowlitz River System." U. S. Geological Survey Professional Paper 1447-A.

Sheridan, M. F. et al. 2005. "Evaluating Titan2D Mass-Flow Model Using the 1963 Little Tahoma Peak Avalanches, Mount Rainier, Washington." Journal of Volcanology and Geothermal Research.

Spataro, William, Donato D’Ambrosio, Rocco Rongo, and Giuseppe A. Trunfio. 2004. “An Evolutionary Approach for Modelling Lava Flows through Cellular Automata." Lecture Notes in Computer Science (including subseries Lecture Notes in Artificial Intelligence and Lecture Notes in Bioinformatics).

Stevens, N. F., V. Manville, and D. W. Heron. 2003. "The Sensitivity of a Volcanic Flow Model to Digital Elevation Model Accuracy: Experiments with Digitised Map Contours and Interferometric SAR at Ruapehu and Taranaki Volcanoes, New Zealand." Journal of Volcanology and Geothermal Research 119(1-4): 89-105.

Stevenson, John A., and Nick Varley. 2008. "Fumarole Monitoring with a Handheld Infrared Camera: Volcán de Colima, Mexico, 2006-2007." Journal of Volcanology and Geothermal Research.

Stinton, AJ et al. 2004. "Incorporation of Variable Bed Friction into Titan2D Mass-Flow Model: Application to Little Tahoma Peak Avalanches (Washington)." Acta Vulcanologica 16(1-2): 153-64.

http://scholar.google.com/scholar?hl=en\&btnG=Search\&q=intitle:INCORPORATION+OF+VARI ABLE+BED+FRICTION+INTO+TITAN2D+MASS- 
FLOW+MODEL:+APPLICATION+TO+LITTLE+TAHOMA+PEAK+AVALANCHES+(+WASHINGTON+) $\# 0$.

Sulpizio, R. et al. 2010. “Predicting the Block-and-Ash Flow Inundation Areas at Volcán de Colima (Colima, Mexico) Based on the Present Day (February 2010) Status." Journal of Volcanology and Geothermal Research 193(1-2): 49-66. http://dx.doi.org/10.1016/j.jvolgeores.2010.03.007.

- - 2016. "The Influence of Slope-Angle Ratio on the Dynamics of Granular Flows: Insights from Laboratory Experiments." Bulletin of Volcanology 78(11). http://dx.doi.org/10.1007/s00445-016-1069-5.

Sulpizio, R., P. Dellino, D. M. Doronzo, and D. Sarocchi. 2014. “Pyroclastic Density Currents: State of the Art and Perspectives." Journal of Volcanology and Geothermal Research 283: 36-65. http://dx.doi.org/10.1016/j.jvolgeores.2014.06.014.

Sulpizio, Roberto, and Pierfrancesco Dellino. 2008. “Chapter 2 Sedimentology, Depositional Mechanisms and Pulsating Behaviour of Pyroclastic Density Currents." Developments in Volcanology 10(C): 57-96.

Vallance, James W., and Richard M. Iverson. 2015. The Encyclopedia of Volcanoes Lahars and Their Deposits. Second Edi. Elsevier. http://dx.doi.org/10.1016/B978-0-12-385938-9.00037-7.

Vallance, James W. 2005. "Volcanic Debris Flows." In Debris-Flows Hazard and Related Phenomena, eds. M. Jakob and O. Hungr. Springer Berlin Heidelberg, 247-74.

Yen, Ben Chie. 1973. “OPEN-CHANNEL FLOW EQUATIONS REVISITED.” ASCE J Eng Mech Div.

Yu, Bin et al. 2009. “Numerical Issues in Computing Inundation Areas over Natural Terrains Using Savage-Hutter Theory." Natural Hazards 50(2): 249-67.

Zanchetta, G. et al. 2004. "Characteristics of May 5-6, 1998 Volcaniclastic Debris Flows in the Sarno Area (Campania, Southern Italy): Relationships to Structural Damage and Hazard Zonation." Journal of Volcanology and Geothermal Research 133(1-4): 377-93. 